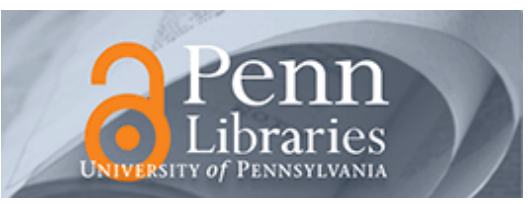

University of Pennsylvania

ScholarlyCommons

\title{
They See Us as Less Than Human: Metadehumanization Predicts Intergroup Conflict via Reciprocal Dehumanization
}

\author{
Nour Kteily \\ Gordon Hodson \\ Emile Bruneau \\ University of Pennsylvania, emile.bruneau@asc.upenn.edu
}

Follow this and additional works at: https://repository.upenn.edu/asc_papers

Part of the Cognition and Perception Commons, Cognitive Psychology Commons, Community Psychology Commons, Gender, Race, Sexuality, and Ethnicity in Communication Commons, International and Area Studies Commons, International and Intercultural Communication Commons, Mass Communication Commons, Personality and Social Contexts Commons, Social Influence and Political Communication Commons, and the Social Psychology Commons

\section{Recommended Citation}

Kteily, N., Hodson, G., \& Bruneau, E. (2016). They See Us as Less Than Human: Metadehumanization Predicts Intergroup Conflict via Reciprocal Dehumanization. Journal of Personality and Social Psychology, 110 (3), 343-370. https://doi.org/10.1037/pspa0000044

Supplemental material is available at http://dx.doi.org/10.1037/pspa0000044.supp

This paper is posted at ScholarlyCommons. https://repository.upenn.edu/asc_papers/570

For more information, please contact repository@pobox.upenn.edu. 


\title{
They See Us as Less Than Human: Metadehumanization Predicts Intergroup Conflict via Reciprocal Dehumanization
}

\begin{abstract}
Although the act of dehumanizing an outgroup is a pervasive and potent intergroup process that drives discrimination and conflict, no formal research has examined the consequences of being dehumanized by an outgroup-that is, "metadehumanization." Across 10 studies $(N=3,440)$ involving several real-world conflicts spanning 3 continents, we provide the first empirical evidence that metadehumanization (a) plays a central role in outgroup aggression that is (b) mediated by outgroup dehumanization, and (c) distinct from metaprejudice. Studies $1 \mathrm{a}$ and $1 \mathrm{~b}$ demonstrate experimentally that Americans who learn that Arabs (Study 1a) or Muslims (Study 1b) blatantly dehumanize Americans are more likely to dehumanize that outgroup in return; by contrast, experimentally increasing outgroup dehumanization did not increase metadehumanization (Study 1c). Using correlational data, Study 2 documents indirect effects of metadehumanization on Americans' support for aggressive policies toward Arabs (e.g., torture) via Arab dehumanization. In the context of Hungarians and ethnic minority Roma, Study 3 shows that the pathway for Hungarians from metadehumanization to aggression through outgroup dehumanization holds controlling for outgroup prejudice. Study 4 examines Israelis' metaperceptions with respect to Palestinians, showing that: (a) feeling dehumanized (i.e., metadehumanization) is distinct from feeling disliked (i.e., metaprejudice), and (b) metadehumanization uniquely influences aggression through outgroup dehumanization, controlling for metaprejudice. Studies $5 \mathrm{a}$ and $5 \mathrm{~b}$ explore Americans' metaperceptions regarding ISIS and Iran. We document a dehumanization-specific pathway from metadehumanization to aggressive attitudes and behavior that is distinct from the path from metaprejudice through prejudice to aggression. In Study 6, American participants learning that Muslims humanize Americans (i.e., metahumanization) humanize Muslims in turn. Finally, Study 7 experimentally contrasts metadehumanization and metahumanization primes, and shows that resulting differences in outgroup dehumanization are mediated by (a) perceived identity threat, and (b) a general desire to reciprocate the outgroup's perceptions of the ingroup. In summary, our research outlines how and why metadehumanization contributes to cycles of ongoing violence and animosity, providing direction for future research and policy.
\end{abstract}

\section{Keywords}

dehumanization, metadehumanization, conflict resolution, intergroup relations, metaperceptions

\section{Disciplines}

Cognition and Perception | Cognitive Psychology | Communication | Community Psychology | Gender, Race, Sexuality, and Ethnicity in Communication | International and Area Studies | International and Intercultural Communication | Mass Communication | Personality and Social Contexts | Social and Behavioral Sciences | Social Influence and Political Communication | Social Psychology

\section{Comments}

Supplemental material is available at http://dx.doi.org/10.1037/pspa0000044.supp 


\title{
They See Us As Less Than Human: Meta-Dehumanization Predicts Intergroup Conflict Via Reciprocal Dehumanization
}

\author{
Nour Kteily ${ }^{\mathrm{a}}$, Gordon Hodson ${ }^{\mathrm{b}}$, Emile Bruneau $^{\mathrm{c}}$
}

la Department of Management and Organizations, Northwestern University, Evanston, IL 60208

${ }^{\mathrm{b}}$ Department of Psychology, Brock University, St Catharines, ON, Canada L2S 3A1

${ }^{\mathrm{c}}$ Annenberg School for Communication, University of Pennsylvania, Philadelphia, PA 19104

Corresponding Author:

Nour Kteily (n-kteily@kellogg.northwestern.edu) 


\title{
RUNNING HEAD: THEY SEE US AS LESS THAN HUMAN
}

\begin{abstract}
Although the act of dehumanizing an outgroup is a pervasive and potent intergroup process that drives discrimination and conflict, no formal research has examined the consequences of being dehumanized by an outgroup - i.e. 'meta-dehumanization'. Across ten studies $(\mathrm{N}=3,440)$ involving several real-world conflicts spanning three continents, we provide the first empirical evidence that meta-dehumanization (a) plays a central role in outgroup aggression that is (b) mediated by outgroup dehumanization, and (c) distinct from meta-prejudice. Studies $1 \mathrm{a}$ and $1 \mathrm{~b}$ demonstrate experimentally that Americans receiving information that Arabs (Study 1a) or Muslims (Study 1b) blatantly dehumanize Americans are more likely to dehumanize that outgroup in return; by contrast, experimentally increasing outgroup dehumanization did not increase metadehumanization (Study 1c). Using correlational data, Study 2 documents indirect effects of meta-dehumanization on Americans' support for aggressive policies towards Arabs (e.g., torture) via Arab dehumanization. In the context of Hungarians and ethnic minority Roma, Study 3 shows that the pathway for Hungarians from meta-dehumanization to aggression through outgroup dehumanization holds controlling for outgroup prejudice. Study 4 examines Israelis' meta-perceptions with respect to Palestinians, showing that: (a) feeling dehumanized (i.e., meta-dehumanization) is distinct from feeling disliked (i.e., meta-prejudice), and (b) meta-dehumanization uniquely influences aggression through outgroup dehumanization, controlling for meta-prejudice. Studies 5a and 5b explore Americans' meta-perceptions regarding ISIS and Iran. We document a dehumanizationspecific pathway from meta-dehumanization to aggressive attitudes and behavior that is distinct from the path from meta-prejudice through prejudice to aggression. In Study 6,
\end{abstract}


RUNNING HEAD: THEY SEE US AS LESS THAN HUMAN

American participants learning that Muslims humanize Americans (i.e., metahumanization) humanize Muslims in turn. Finally, Study 7 experimentally contrasts meta-dehumanization and meta-humanization primes, and shows that resulting differences in outgroup dehumanization are mediated by (1) a general desire to reciprocate the outgroup's perceptions of the ingroup, and (2) perceived identity threat. In sum, our research outlines how and why meta-dehumanization contributes to cycles of ongoing violence and animosity, thus providing direction for future research and policy.

Keywords: Dehumanization; Meta-Dehumanization; Conflict Resolution; Intergroup Relations; Meta-perceptions; Stigma; Prejudice 
RUNNING HEAD: THEY SEE US AS LESS THAN HUMAN

\section{They See Us As Less Than Human: Meta-Dehumanization Predicts Intergroup Conflict Via Reciprocal Dehumanization}

In early September 2012, a 14-minute video titled Innocence of Muslims, dubbed in Arabic, appeared on YouTube. It soon emerged that this video had been shot in the United States by an American resident of Egyptian origin. The video depicted the Prophet Muhammad, an act viewed throughout the Muslim world as an offence. Worse, the Prophet was portrayed not just in a negative light, but specifically in animalistic terms: as an incompetent buffoon, a hyper-sexual womanizer lacking in self-control, and a "bloodthirsty" leader of a savage, "ragtag group of men who enjoy killing” (BBC News, 2012). The response to this depiction was swift and violent. Within days of the film's release, anti-American protests erupted in Egypt and quickly spread to American embassies in a number of cities around the world, leaving scores dead and hundreds of others injured, and causing outrage among the American populace (BBC News, 2012). Capturing the mood at the time, Rifaei Taha, a leader of a political party in Egypt, reciprocated the dehumanization he perceived, calling on then-President Mohammad Morsi to "cut relations with those [American] monkeys and pigs" (CBS News, 2012). How might the more powerful group (here, Americans), react to being dehumanized by the lower status 'other'? Might such meta-perceptions predict increasingly hostile intergroup responses, including reciprocal dehumanization and collective aggression, thus contributing to the vicious cycles that have marred so many longstanding conflicts?

We sought to specifically explore the effects of this perception that one's own group is perceived by another as less than fully human - i.e., 'meta-dehumanization'. A large and growing literature has detailed the pervasiveness of dehumanization, its 
RUNNING HEAD: THEY SEE US AS LESS THAN HUMAN

uniqueness from prejudice (e.g., Andrighetto, Baldissarri, Lattanzio, Loughnan, \& Volpato, 2014; Haslam, 2006; Leyens et al., 2000, 2007) and its potency in legitimizing intergroup aggression (Kteily, Bruneau, Waytz, \& Cotterill, 2015; Struch \& Schwarz, 1989; Viki, Osgood, \& Phillips, 2013; see also Bandura, Barbaranelli, Caprara, \& Pastorelli, 1996). At the same time, despite the fact that negative meta-perceptions more broadly construed (e.g., meta-stereotypes; meta-prejudice) are known to have damaging effects on intergroup relations (Frey \& Tropp, 2006; Kamans et al., 2009; Owuamalam, Issmer, Zagefka, Klaben, \& Wagner, 2014; Vorauer, Main, \& O’Connell, 1998), no prior work has examined how individuals respond to the (meta)perception that their group is dehumanized. If blatant dehumanization is such a strong and unique predictor of negative intergroup outcomes, might meta-dehumanization also galvanize hostile intergroup processes over and above other negative meta-perceptions? Focusing on intensive realworld intergroup conflicts such as the Israeli-Palestinian conflict and American-Muslim relations, the present work considers the effects of perceiving that one's group is not just disliked, but actively and blatantly dehumanized by the outgroup.

The central hypothesis of this work is that perceiving that one's ingroup is blatantly dehumanized by an outgroup can provoke individuals to reciprocate by dehumanizing that group in turn, thus increasing support for violent and aggressive collective actions against it. We argue further that this will occur over and above any effects of (a) meta-perceptions of prejudice, and (b) any outgroup prejudice that metaprejudice might provoke. That is, we propose a novel dehumanization-specific path from meta-dehumanization to outgroup aggression through reciprocal dehumanization. 
RUNNING HEAD: THEY SEE US AS LESS THAN HUMAN

The question of how group members respond to perceived outgroup dehumanization of their group is both theoretically important and practically relevant. Our work combines insights from the largely separate literatures on dehumanization and meta-perceptions, extending theory in each. We advance the literature on intergroup dehumanization by considering how meta-perceptions can lead to intergroup hostility through entrenching dehumanization, and broaden the scope of research on metaperceptions by identifying a unique and consequential type of meta-perception. Practically, if meta-dehumanization indeed promotes outgroup dehumanization and thus more aggressive outgroup attitudes and behavior, it has the potential to contribute importantly to vicious cycles of intergroup conflict (e.g., Bar-Tal, 2000; Kelman, 1987). Therefore, understanding the role of meta-dehumanization, the mechanisms underlying its effects, and the ways in which it can be attenuated has important implications for the prospects of intergroup harmony.

Below, we briefly review the existing literatures on each of negative intergroup meta-perceptions and dehumanization, and then consider how meta-dehumanization might uniquely influence outgroup attitudes and behavior.

\section{Responses to Intergroup Meta-Perceptions}

Vorauer et al. (1998) introduced the term meta-stereotyping to describe the content of individuals' cognitions about how they are perceived by an outgroup. This research focused on the dominant group's (e.g., White Canadians) sense of how they are perceived by a subordinate group (e.g., Aboriginal Canadians) in the context of a crossgroup interpersonal encounter. These authors showed that White Canadians expected Aboriginal Canadians to stereotype them with a mixture of positive and negative traits: as 
RUNNING HEAD: THEY SEE US AS LESS THAN HUMAN

high status and ambitious, but also as egocentric, unfeeling, selfish, and prejudiced. Importantly, the more White Canadians expected to be stereotyped, the less they anticipated enjoying contact with an outgroup member, and the more prejudice they exhibited towards the outgroup. Moreover, in an actual interaction with an outgroup member, feeling meta-stereotyped was associated with threat to individuals' self-concept. This research illustrated the potency of meta-perceptions by showing that they played an even bigger role in affecting the intergroup interaction than the stereotypes participants themselves held about the outgroup (e.g., seeing Aboriginal Canadians as lazy; see also Vorauer \& Kumhyr, 2001). Consistent with this perspective, other research has documented the aversive effects of engaging in or anticipating intergroup encounters, attributable in part to expectations of (and anxiety about) being negatively evaluated by an outgroup individual (Richeson \& Shelton, 2007; Vorauer, Hunter, Main, \& Roy, 2000; see also MacInnis \& Hodson, 2012).

Expecting to be viewed negatively by another group can lead not only to avoidance of and discomfort with intergroup interactions, but also to increased intergroup bias (Paolini, Hewstone, Voci, Harwood, \& Cairns, 2006) and hostility (Kamans et al., 2009). Why might individuals respond to negative meta-perceptions by reciprocating that negativity in kind? Research on social identity threat (Branscombe, Ellemers, Spears, \& Doosje, 1999) suggests that because individuals derive esteem from their membership in groups (Tajfel \& Turner, 1986), they experience devaluation of their group as an aversive threat that they seek to remedy (see also Hornsey, 2008). One means by which individuals might restore ingroup status is by derogating the outgroup responsible for the status threat (e.g., Bourhis, Giles, Leyens, \& Tajfel, 1979; Branscombe, Schmitt, \& 
RUNNING HEAD: THEY SEE US AS LESS THAN HUMAN

Harvey, 1999; Branscombe \& Wann, 1994), especially when the status threat is perceived as illegitimate or offensive, and thus rejected out of hand (Ellemers, Wilke, \& Van Knippenberg, 1993; Vorauer \& Sakamoto, 2008; see also Jetten, Schmitt, \& Branscombe, 2013).

Indeed, there is good evidence that individuals reciprocate negative evaluations they perceive from others, and become more willing to endorse hostile behavior towards them (Bourhis et al., 1979; Devine, Evett, \& Vasquez-Suson, 1996; Kamans et al., 2009). For example, Belgian Flemish speakers experimentally exposed ( $v s$. not exposed) to a French-speaking Belgian confederate insulting the Flemish language were more likely to retaliate by directing obscenities at the offender (Bourhis et al., 1979). Moroccans in the Netherlands who harbored negative attitudes towards the majority-Dutch and expected them to perceive Moroccans negatively (e.g., as 'criminal' or 'aggressive') were more likely to endorse aggressive behavior against them (Kamans et al., 2009). Other research has also shown that individuals who activate negative group meta-perceptions are more likely to respond with anger and reciprocal negativity towards the offending outgroup (Owuamalam, Tarrant, Farrow, \& Zagefka, 2013), and to support collective action to seek redress (Owuamalam et al., 2014). Finally, examining the Eurovision song contest, Doosje and A. Haslam (2005) showed that reciprocation of outgroup actions and perceptions extends to behavior: members of European nations punished nations that had voted for the ingroup less in previous years by voting for them less; they also rewarded nations that had previously favored the ingroup with more votes.

In sum, people think about how they are perceived by other groups, and these meta-perceptions are frequently negative in content (Frey \& Tropp, 2006). Because they 
RUNNING HEAD: THEY SEE US AS LESS THAN HUMAN

impact the ingroup's social identity, negative meta-perceptions are experienced as aversive and threatening. This promotes desires to restore ingroup status, a goal that can be achieved by derogating the offending outgroup in kind. Consistent with this, individuals who perceive that their group is viewed negatively oftentimes reciprocate: they respond with anger, hostile outgroup evaluations, and even support for aggression and collective action against the outgroup, particularly when the meta-perception is viewed as inaccurate and offensive. Despite this prior research, no work has examined the (meta)-perception that another group perceives the ingroup as less than fully human. As we develop further below, perceiving that another group blatantly dehumanizes the ingroup represents a stark and harsh devaluation of the ingroup that we hypothesize would be viewed as particularly offensive, and is likely to be reciprocated in kind.

\section{Intergroup Dehumanization}

In parallel to work on negative meta-perceptions, a growing body of research has examined dehumanization and its effects on intergroup (and interpersonal) relations. This research has examined both blatant and subtle forms of dehumanization. Early research focused on the role of blatant dehumanization in licensing aggression. For example, Bandura, Underwood, and Fromson (1975) showed that participants who 'mistakenly' overheard an experimenter describe subjects using dehumanizing (vs. humanizing, or neutral) language provided more intense shocks to these (purported) participants when they erred (see also Struch \& Schwarz, 1989). The facilitating effect of blatant dehumanization on aggression was explained by the fact that dehumanization places the target outside the scope of moral consideration (see also Kelman, 1976; Opotow, 1990). Speaking to the unique power of dehumanization, Kelman (1976) noted that fear or 
RUNNING HEAD: THEY SEE US AS LESS THAN HUMAN

intense dislike do not preclude seeing an enemy as a human, and indeed may even afford that enemy a certain level of respect; in contrast, when another is viewed as less than human moral restraints are removed and violence is condoned (or even encouraged).

Contemporary research has additionally explored the variety of indirect ways in which we engage in 'everyday' dehumanization. Whereas blatant dehumanization involves the active and deliberate denial of others' humanity, subtle dehumanization may occur even outside conscious awareness (Haslam, 2014; Leyens et al., 2000; Leyens, Demoulin, Vaes, Gaunt, \& Paladino, 2007). The process of viewing athletes as statistics, women as objects, inmates as numbers, and sick individuals as 'patients' may involve attributing them fewer traits unique to humans and central to our nature, reflecting a subtle denial of what it means to be fully human (e.g., Haslam, 2006; Waytz, Schroeder, \& Epley, 2014; see also Bain, Vaes, \& Leyens, 2014). In the intergroup domain, pioneering work on infrahumanization (Leyens et al., 2000) showed that individuals attribute complex secondary emotions (more closely associated with humans than animals) to members of their own group than an outgroup (see also Demoulin et al., 2004). Building on this work, Haslam (2006) posited two bases of dehumanization: Animalistic dehumanization, akin to infrahumanization, involves the relative underattribution to others of characteristics (e.g., cognitive aptitude, refinement, civility) considered unique to humans; mechanistic dehumanization, on the other hand, involves denying others traits (e.g., warmth, emotionality) that, while central to being human, may also be shared with animals (see Haslam, Bain, Douge, Lee, \& Bastian, 2005). Importantly, by showing that individuals preferentially attribute both positive and negative secondary emotions (and characteristics) to the ingroup, the research on 


\section{RUNNING HEAD: THEY SEE US AS LESS THAN HUMAN}

infrahumanization and animalistic/mechanistic dehumanization differentiates these phenomena from simple outgroup negativity (Albarello \& Rubini, 2012; Andrighetto et al., 2014; Leyens et al., 2000).

A number of studies have now illustrated the intergroup consequences of subtly dehumanizing outgroups and shown that they can occur in parallel with (or in addition to) outgroup prejudice. For example, research has shown that infrahumanization is associated with decreased helping intentions after Hurricane Katrina (Cuddy, Rock, \& Norton, 2007), and that it reduces acceptance of responsibility for past ingroup wrongdoings (Castano \& Giner-Sorolla, 2006). Similarly, Andrighetto and colleagues (2014) showed that Italians' unwillingness to help outgroup members (Japanese and Haitians) after a natural disaster is predicted by their animalistic (Haitians) and mechanistic (Japanese) dehumanization of these groups, controlling statistically for outgroup prejudice.

Although this past dehumanization research indicates that both blatant and subtle dehumanization are relevant to intergroup processes and distinct from prejudice, these forms of dehumanization had not been directly contrasted until very recently. Kteily et al. (2015) provided the first formal comparison of the effects of blatant dehumanization relative to subtle dehumanization (i.e., infrahumanization; animalistic/mechanistic dehumanization) on intergroup attitudes and behavior, examining contexts marked by open hostility and intergroup conflict (e.g., American-ISIS relations). Using their newly developed 'Ascent scale of blatant dehumanization', these authors argued that blatant dehumanization — so central to past intergroup conflicts — remains a feature of contemporary society. Across a range of contexts they showed that blatant (vs. subtle) dehumanization is a stronger predictor of extreme intergroup attitudes (such as support 
RUNNING HEAD: THEY SEE US AS LESS THAN HUMAN

for torture, and drone strikes) and behavior (such as signing online petitions in support of militarism). The effects of blatant dehumanization held controlling for outgroup prejudice, confirming a distinction between dehumanization and dislike (see also Goff, Eberhardt, Williams, \& Jackson, 2008; Goff et al., 2014) that also receives neuroimaging support (Bruneau, Jacoby, Kteily, Ligouri, \& Saxe, under review).

In sum, considerable progress has been made in understanding when, why, and how we dehumanize other targets. This research suggests that conflictual intergroup contexts continue to be marked by blatant outgroup dehumanization, a potent perception distinguishable from both subtle dehumanization and outgroup prejudice. Yet the vast majority of this research has focused on the dehumanization of others (e.g., 'they are animal-like'), with little known about the consequences of feeling dehumanized by others (i.e., 'they think we are animal-like'), a perception that may well feature in the context of intergroup conflict. This lacuna is surprising, given both the prevalence of dehumanization research and the recognized importance of meta-perceptions to intergroup relations (e.g., Frey \& Tropp, 2006; Yzerbyt, Judd, \& Muller, 2009).

\section{Integrating Theorizing on Meta-perceptions and Dehumanization}

Here we integrate insights from research on negative meta-perceptions and on blatant dehumanization. Specifically, combining the knowledge that individuals often reciprocate negativity they perceive from outgroups, and the fact that blatant dehumanization is distinct from outgroup prejudice, we ask whether feeling dehumanized ( $v s$. disliked or negatively stereotyped) by another group can uniquely contribute to intergroup hostilities by increasing outgroup dehumanization. There are a number of theoretical arguments in favor of this possibility. First, previous research demonstrates 
RUNNING HEAD: THEY SEE US AS LESS THAN HUMAN

that outgroup dehumanization is conceptually and empirically distinct from outgroup prejudice, and also that it is uniquely associated with outgroup aggression (Kteily et al., 2015). Second, given that (blatant) dehumanization involves extreme devaluation, and outright exclusion from the moral domain (Kelman, 1976) and the most basic shared superordinate identity of 'human', meta-dehumanization should provoke particularly strong threats to ingroup identity. In line with theorizing suggesting that individuals respond in kind to outgroups' negative perceptions of the ingroup (Branscombe et al., 1999a), meta-dehumanization may provoke very harsh responses, including reciprocal dehumanization of — and aggression towards — the offending outgroup.

Some recent research in the interpersonal domain provides support for our notion that individuals dehumanize those who they perceive to dehumanize them. Bastian and Haslam (2010) showed that people socially excluded (vs. included) in a Cyberball game were significantly more likely to report that that target treated them as less human (Bastian \& Haslam, 2010, Study 2). This led participants to dehumanize the ostracizer, primarily by attributing them fewer traits considered central to human nature, such as emotionality and warmth (see Haslam, 2006). Relatedly, Bastian and Haslam (2011) found that participants who were asked to vividly recall a time when they were treated as irrelevant or unimportant (i.e., mechanistically dehumanized) reported feeling more numbness, lethargy, and sadness (presumably reflecting the pain of the meta-perception), but also more anger (presumably towards the perpetrator). Thus, existing research on interpersonal processes suggests that feeling excluded or undervalued by others can be painful, and we may reciprocate that negativity. 
RUNNING HEAD: THEY SEE US AS LESS THAN HUMAN

In the present research, we examine blatant ( $v s$. subtle) forms of metadehumanization, and focus on conflictual intergroup ( $v s$. interpersonal) contexts, which tend to involve greater competitiveness and aggression (Wildschut, Pinter, Vevea, Insko, \& Schopler, 2003). In this context, we reason that individuals will be highly likely to feel threatened by the outgroup's perception and reciprocate any dehumanization they perceive. Extending prior work, we distinguish for the first time between metadehumanization and other negative meta-perceptions.

\section{Hypotheses}

In line with prior research on responses to negative meta-perceptions, we hypothesized that perceiving that the ingroup is blatantly dehumanized by an outgroup would predict greater blatant dehumanization of that outgroup (see Figure 1 for a diagram of our overall conceptual model). Consistent with previous work (Kteily et al., 2015), we hypothesized that outgroup dehumanization would itself be associated with support for aggressive intergroup attitudes and behaviors, such as support for torture and collective aggression, independent of outgroup prejudice (i.e., dislike). Thus, we expected that meta-dehumanization would indirectly affect aggressive outgroup attitudes and behavior via outgroup dehumanization (i.e., a significant $a * b$ path; see Figure 1). Consistent with previous research highlighting the importance of meta-perceptions beyond outgroup perceptions (e.g., Vorauer et al., 1998), we also considered the possibility that metadehumanization might exert direct effects (i.e., significant c path) on the outcome variables. We hypothesized that effects of meta-dehumanization would be theoretically independent from meta-prejudice, or the perception that the outgroup dislikes the ingroup. Finally, we hypothesized that the effects of meta-dehumanization would be 
RUNNING HEAD: THEY SEE US AS LESS THAN HUMAN

unique from political ideologies such as social dominance orientation, right-wing authoritarianism, and conservatism, previously shown to be associated with dehumanization (e.g., Costello \& Hodson, 2010, 2014; Hodson \& Costello, 2007; Kteily et al., 2015) and aggressive intergroup attitudes (e.g., Hetherington \& Suhay, 2011; Kteily, Ho, \& Sidanius, 2012; Kteily, Cotterill, Sidanius, Sheehy-Skeffington, \& Bergh, 2014).

\section{Overview of Studies}

We examined our hypotheses across ten samples. In Studies 1a and 1b we used two separate experimental manipulations to examine whether meta-dehumanization causes outgroup dehumanization among community samples of Americans in the context of American-Arab relations (Study 1a; $N=210$ ) and American-Muslim relations (Study 1b; $N=214)$. In Study 1c, we experimentally examined whether there was any evidence for the reverse causal pathway (i.e., from dehumanization of Muslims to metadehumanization; $N=213$ Americans). In Study 2, we cross-sectionally examined whether meta-dehumanization in American-Arab relations was associated with hostile intergroup attitudes and policy support through greater outgroup dehumanization $(N=270)$. In Study 3, we again tested the meta-dehumanization $\rightarrow$ dehumanization $\rightarrow$ hostile attitudes pathway, but among a large sample of ethnic Hungarians $(N=906)$, further controlling for outgroup prejudice toward the Roma. In Study 4, we considered Israelis' $(N=493)$ meta-perceptions about Palestinians, examining not only meta-dehumanization but also meta-prejudice ("they dislike us"), to address whether meta-dehumanization effects predict beyond meta-perceptions that are simply negative in valence. In Studies $5 \mathrm{a}(N=$ 366) and $5 \mathrm{~b}(N=310)$, we explored the extent to which Americans feel dehumanized by 
RUNNING HEAD: THEY SEE US AS LESS THAN HUMAN

ISIS (in the aftermath of the Charlie Hebdo attacks; Study 5a) and Iran (shortly after the announcement of the nuclear deal; Study 5b), and examined how this was uniquely associated with hostile attitudes and behavior. In Study $6(N=211)$, we experimentally examined whether learning that Muslims humanized Americans (i.e., meta-humanization) could reduce outgroup dehumanization. Finally, in Study $7(N=231)$, we examined the mechanism underlying the relationship between meta-perceptions about outgroup ratings of ingroup humanity and outgroup dehumanization.

\section{Study 1a}

In Study 1a, we sought to examine the experimental effect of metadehumanization. Specifically, we tested our prediction that Americans who learn that they are dehumanized by Arabs will be more likely to dehumanize Arabs in turn.

\section{Method}

Participants. We collected data from 216 participants through Amazon Mechanical Turk, a reliable and high-quality platform for recruiting diverse samples (Buhrmester, Kwang, \& Gosling, 2011) in June 2015. We excluded 6 participants not native to the U.S. leaving 210 participants $(M$ age $=31.68, S D=11.55 ; 51.9 \%$ male; 74.8\% White American, 9.0\% Black American; 7.6\% Asian American; 5.2\% Latino/Hispanic American; 1.0\% Native American; 2.4\% Biracial/mixed race).

Procedure. Participants filled out demographic information and items assessing patriotism and nationalism, and were then told that we were interested in "people's social, economic, and political perceptions and how they compare across cultures". Participants read that we had previously conducted "an online survey very similar to the one you are now completing among large samples of Arabs living in each of 5 different 
RUNNING HEAD: THEY SEE US AS LESS THAN HUMAN

and diverse countries: Lebanon, Egypt, Saudi Arabia, Jordan, and Yemen”. The survey was purported to measure Arabs' perceptions of how the political system in their societies functions, their sense of corruption in their social system, their attitudes towards religion, and their perception of Americans. Participants were then told that they would see some of the questions that Arab participants answered and their responses.

Participants were then provided with the Arab responses. Specifically, participants received demographic information about the purported Arab sample, including country of origin, average age, and religion. They also received (filler) information about their supposed social networks, and their attitudes relating to political transparency in their country. Next, participants saw the results of Arabs' (purported) perception of Americans, with all participants learning that Arabs felt warmer towards their own group (Arabs) than towards Americans (i.e., Arab prejudice towards Americans was held constant).

After seeing Arab warmth towards Americans, participants were provided with the information central to our manipulation: Arab ratings of Arabs and Americans on the Ascent Dehumanization scale (Kteily et al., 2015; see Figure 2 for depiction of the Ascent scale). In the control condition, participants learned that Arabs had rated Arabs and Americans to be highly and equally evolved (i.e., around 96 on the unmarked 0-100 Ascent scale). In the experimental condition ('high meta-dehumanization'), participants learned that Arabs had rated Arabs as highly evolved (i.e., 96 on the Ascent scale), but rated Americans substantially lower (i.e., around 67 on the Ascent scale). After reading this information, participants saw a final item indicating Arabs' purported feelings about their family's economic situation (constant across conditions). 
RUNNING HEAD: THEY SEE US AS LESS THAN HUMAN

Consistent with the cover story that we were interested in cross-cultural comparisons between Arabs and Americans on a range of metrics, we next gave participants a series of filler questions that matched the types of questions we had supposedly asked Arabs (e.g., perceptions of corruption in the U.S.; questions about their social network). Subsequently, we moved on to the question of central interest: blatant dehumanization of Arabs.

\section{Outcome Measures.}

We first assessed meta-dehumanization and meta-prejudice, presented in randomized order.

Meta-dehumanization. As a manipulation check, we assessed the extent to which participants perceived that Arabs dehumanized Americans. Specifically, we asked participants to indicate their agreement with each of the following items on a 1 (Strongly Disagree) to 7 (Strongly Agree) scale: "Arabs perceive Americans to be sub-human", "Arabs think of Americans as animal-like", "Arabs see Americans as less evolved than other groups", "Arabs think Americans are beasts", and "Arabs consider Americans to belong to a lower form of civilization" $(\alpha=.95)$.

Meta-prejudice. We assessed the extent to which participants felt that they were disliked by Arabs on a 1 (Strongly Disagree) to 7 (Strongly Agree) scale, asking them to indicate their agreement with the following two items: "Arabs feel cold towards Americans", and "Arabs do not have positive attitudes towards Americans" $(r=.78, p<$ $.001)$.

Next, we assessed dehumanization and prejudice, presented in randomized order. 
RUNNING HEAD: THEY SEE US AS LESS THAN HUMAN

Dehumanization. We assessed participants' dehumanization of Arabs by using the Ascent scale of blatant dehumanization (Kteily et al., 2015). Specifically, participants rated the average 'evolvedness' of members of a series of groups, including Arabs and Americans, using an unmarked slider bar. The scale is scored from 0-100, with 100 indicating full humanity. In order to assess dehumanization of Arabs, we reversed scores such that higher scores indicate more dehumanization.

Prejudice. We assessed prejudice towards Arabs using the widely-used feeling thermometer (Haddock, Zanna, \& Esses, 1993). Specifically, participants rated how warm they felt towards members of a series of groups, including Arabs, using an unmarked slider bar anchored at 0 ('very cold and unfavorable') and 100 ('very warm and favorable). Scores were reversed such that higher scores indicate more prejudice towards Arabs.

Attention check. Finally, we asked participants two questions designed to assess their level of attention to the experimental materials that they had been provided. Each of the two questions tested whether they could correctly recall which topics had not been mentioned in the survey report purportedly completed by Arabs. We excluded participants $(n=55)$ who incorrectly answered one of these two questions, leaving a total sample of 155 participants for the remaining analyses $(M$ age $=32.06, S D=11.45 ; 51.0 \%$ male; 78.1\% White American; 7.1\% Black American; 6.5\% Asian American; 5.8\% Latino/Hispanic American; 2.6\% Biracial/mixed race). ${ }^{1}$

\section{Results}

We first assessed whether our manipulation had successfully influenced participants' perception of the extent to which Arabs dehumanized Americans. Indeed, 
RUNNING HEAD: THEY SEE US AS LESS THAN HUMAN

those participants who saw the survey results suggesting that Arabs dehumanize Americans were significantly more likely to report that they were dehumanized by Arabs $(M=4.05, S D=1.65)$ than were those who reported that Arabs perceived both Arabs and Americans as highly (and equally) evolved $(M=2.36, S D=1.29), F(1,153)=49.20, p<$ .001 , partial $\eta^{2}=.24$. There was also a significant but smaller effect of the metadehumanization manipulation on participants' sense that they were disliked by Arabs (high meta-dehumanization condition: meta-prejudice $M=4.88, S D=1.25$; low metadehumanization condition: meta-prejudice $M=4.29, S D=1.32), F(1,153)=8.18, p=$ .005 , partial $\eta^{2}=.05$

We next examined how the experimental manipulation influenced participants' own dehumanization of, and prejudice towards, Arabs. As predicted, American participants in the high meta-dehumanization condition were significantly more likely to dehumanize Arabs in turn $(M=28.22, S D=27.92)$ than those in the control condition $(M$ $=16.73, S D=22.74 ; F(1,153)=7.81, p=.006$, partial $\left.\eta^{2}=.05\right)^{2}$. Those in the high meta-dehumanization condition also reported greater prejudice towards $\operatorname{Arabs}(M=$ 48.93, $S D=26.52)$ than those in the control condition $(M=38.82, S D=25.49), F(1$, $153)=5.82, p=.02$, partial $\eta^{2}=.04 .^{3}$

In sum, the results of Study 1a showed support for our hypothesis that being exposed to information that one's ingroup is dehumanized by an outgroup can, in turn, cause dehumanization of that outgroup. One potential limitation of Study 1a, however, is that we manipulated meta-dehumanization by giving participants information about how they were perceived by Arabs using the same scale (Ascent) which was used to assess outgroup dehumanization. This may have resulted in participants in the meta- 
RUNNING HEAD: THEY SEE US AS LESS THAN HUMAN

dehumanization condition rating Arabs lower in part simply because seeing lower ratings of another group on the Ascent scale licensed (or shifted norms about) outgroup dehumanization. Furthermore, Study la compared meta-dehumanization to a condition in which participants learned that they were perceived by the outgroup as equally human, making it possible that participants in that condition felt humanized by the outgroup. In Study $1 \mathrm{~b}$, we sought to examine the effect of meta-dehumanization through a different experimental manipulation. Specifically, using a text-based prime, we again tested our prediction that Americans who learn that they are dehumanized by an outgroup (here, Muslims) would be more likely to dehumanize that group in turn. Here, we compared individuals in the meta-dehumanization condition to a control condition in which participants received no information about how they were perceived by the outgroup.

\section{Study 1b}

\section{Method}

Participants. We collected data from 225 participants through Amazon Mechanical Turk in October 2015. Three Muslim participants, six non-native U.S. participants and two participants who asked that their data be excluded from the study were removed from analysis; we focused our analyses on the 214 remaining participants $(M$ age $=33.79, S D=10.22 ; 56.1 \%$ male; $72.4 \%$ White American, 9.8\% Black American; 7.0\% Asian American; 5.6\% Latino/Hispanic American; 2.8\% biracial; 0.9\% Native American; 0.5\% Middle Eastern/Arab American; 0.9\% Other) ${ }^{4}$.

Procedure. After completing demographic information and items assessing conservatism, patriotism and nationalism, participants were told that we were interested in "people's social, economic, and political perceptions and how they might be similar or 
RUNNING HEAD: THEY SEE US AS LESS THAN HUMAN

different across cultures". In the control condition, participants were simply asked to click ahead to the survey questions. In the experimental condition, participants read an article purportedly published in the Boston Globe describing the results of a (fictional) report by the United Nations' Commission on Global Relations, examining public perceptions of Americans in the Muslim world. The news article was entitled "In large parts of Muslim world, Americans perceived as 'animals"” (see Supplementary Materials for full text). In order to invoke meta-dehumanization, the article noted that Muslims across a number of Muslim-majority countries perceived Americans as "brutes, lacking in self-control and sophistication", and highlighted quotations from Muslim respondents describing Americans in animalistic terms. The report noted that these perceptions of Americans were highly normative, held by a majority of Muslims. ${ }^{5}$

Participants' then completed two outcome measures - dehumanization and prejudice - in randomized order.

\section{Outcome Measures.}

Dehumanization. We assessed participants' dehumanization of Muslims in two ways. First, participants rated several groups on the Ascent scale of blatant dehumanization (Kteily et al., 2015), including Muslims and Americans; as in Study 1a, we focused on (reverse-scored) ratings of the outgroup (here, Muslims). Second, we assessed blatant dehumanization of Muslims by asking participants to rate the extent to which a series of animalistic traits described Muslims, adapted from Bastian, Haslam, and Denson (2013) and expanded on in Kteily et al. (2015, Study 5): "backward", “savage", "lacking morals", “cold-hearted", "scientifically/technologically advanced”, "primitive", “aggressive" "barbaric", "refined” (reverse-scored), "rational” (reverse- 
RUNNING HEAD: THEY SEE US AS LESS THAN HUMAN

scored), "capable of self-control" (reverse-scored), "mature" (reverse-scored), "cultured" (reverse-scored), "logical" (reverse-scored), and "responsible" (reverse-scored). Ratings were made for these traits on a scale anchored at 1 ('Not at all') and 7 ('Extremely so'; $\alpha$ $=.96)$. As in Kteily et al. (2015, Study 5), we also assessed blatant dehumanization as a composite by standardizing the two dehumanization scores (i.e., Ascent and the animalistic trait composite) and averaging them together $(r=.60, p<.001)$.

Prejudice. We assessed prejudice towards Muslims as in Study 1a.

After presenting all outcome measures, we provided all participants in the experimental condition with a second text describing Muslims' perceptions of Americans in a humanizing light, in an effort to help reverse the negative effects of the manipulation. Participants were then thoroughly debriefed.

\section{Results}

Analyses indicated a chance failure of randomization with respect to conservatism: specifically, although conservatism was assessed prior to the experimental manipulation, and despite the large sample size, participants in the meta-dehumanization condition ( $v s$. control) were significantly more conservative, $F(1,212)=10.01, p=$ $.002 .^{6}$ Thus, we included conservatism as a covariate in all analyses reported below.

We examined whether the experimental manipulation influenced participants' dehumanization of, and prejudice towards, Muslims. We began by examining the (standardized) blatant dehumanization composite. As predicted, Americans who read the article suggesting that Muslims dehumanized Americans $(M=.13, S E=.08)$ were significantly more likely to themselves dehumanize Muslims than participants in the control condition $\left(M=-.12, S E=.08 ; F(1,211)=4.68, p=.03\right.$, partial $\left.\eta^{2}=.02\right)$. 


\section{RUNNING HEAD: THEY SEE US AS LESS THAN HUMAN}

Examining each of the two dehumanization measures in isolation, we observed a significant effect on the animalistic trait ratings (meta-dehumanization condition: $M=$ 4.08, $S E=.13$; control condition: $M=3.65, S E=.13 ; F(1,211)=5.56, p=.02$, partial $\eta^{2}=.03$, and a trend using the Ascent scale (meta-dehumanization condition: $M=31.38$, $S E=3.10$; control condition: $M=24.71, S E=3.01 ; F(1,211)=2.34, p=.13$, partial $\eta^{2}=$ $.01 .^{7,8}$

In addition to the effects on dehumanization, we also observed that participants in the meta-dehumanization condition reported greater prejudice towards Muslims $(M=$ $55.35, S E=2.80)$ than those in the control condition $(M=45.18, S E=2.71 ; F(1,210)=$ $6.68, p=.01$, partial $\eta^{2}=.03$.

In sum, the results of Study $1 \mathrm{~b}$ converged with those of Study 1a: receiving information that one's ingroup is dehumanized by an outgroup, either through a graphical/visual presentation (Study 1a) or through a text-based manipulation (Study 1b), caused dehumanization of (and prejudice towards) that outgroup in turn. Aside from showing that the effects of meta-dehumanization on dehumanization held across distinct manipulations, Study $1 \mathrm{~b}$ showed that meta-dehumanization increased outgroup dehumanization relative to a control condition in which participants received no information about how they were perceived by the outgroup.

Despite our evidence that meta-dehumanization can cause outgroup dehumanization, it remains possible that the reverse causal pathway also holds. That is, when individuals dehumanize another group, they may become more likely to feel dehumanized by that group: this might occur, for example, simply because an animalistic outgroup seems more likely to itself dehumanize others, because we infer a norm of 
RUNNING HEAD: THEY SEE US AS LESS THAN HUMAN

reciprocal dehumanization among those we dehumanize, or as a motivated rationalization for one's own outgroup dehumanization. In Study 1c, we set out to test the reverse causal pathway from outgroup dehumanization to meta-dehumanization.

\section{Study 1c}

\section{Method}

Participants. We collected data from 220 participants through Amazon Mechanical Turk in October 2015. Six participants non-native to the U.S. and one participant who asked that their data be excluded from the study were removed from analysis, leaving 213 participants $(M$ age $=33.51, S D=10.56 ; 50.2 \%$ female; $79.3 \%$ White American; 5.6\% Black American; 5.6\% Asian American; 5.6\% Latino/Hispanic American; 2.8\% Biracial; 0.9\% Native American).

Procedure. The methodology of Study 1c was similar to Study 1b. Specifically, after filling out the same demographics and ideological measures as in Study 1b, participants were randomly assigned into a control or experimental condition. In the control condition, participants were asked to click ahead to the survey questions. In the experimental condition, participants were asked to "read the following newspaper article describing the conclusions of a recently released report about Muslim-majority societies."

We used a text prime very similar to that used in Study $1 \mathrm{~b}$ (but here manipulating outgroup dehumanization). Specifically, we presented participants with a (purported) Boston Globe article on the results of a (fictional) report from the United Nations' Commission on Human Rights. This article was entitled "In large parts of Muslim world, violence harkens to Dark Age" (see Supplementary Materials for full text). The report purportedly examined the use of violence as a means of punishment and dispute in the 
RUNNING HEAD: THEY SEE US AS LESS THAN HUMAN

Muslim world. It detailed the use of practices such as public whippings and hand amputations as punishment for stealing, and death by stoning and public beheadings as punishment for adultery and drug dealing, which were described using animalistic terms such as "brutal". The report also noted that Muslim survey respondents reported using (and approving of) a number of aggressive actions (e.g., slapping, punching, or biting) in response to personal disputes, which were (purportedly) responsible for a high number of deaths in the Muslim world. Finally, the report noted that these violent actions had deep cultural roots, and were highly normative. ${ }^{9}$

Participants then completed two outcome measures - meta-dehumanization and meta-prejudice - in randomized order.

\section{Outcome Measures.}

Meta-Dehumanization. We assessed meta-dehumanization as in Study 1a (but with respect to Muslims), with the exception that the item referring to 'beasts' was replaced with "Muslims consider Americans to be uncivilized". Items were assessed on a 1 ('Strongly Disagree') to 7 ('Strongly Agree') scale ( $\alpha=.95)$.

Meta-Prejudice. We assessed meta-prejudice using the following items:

"Muslims feel cold toward Americans", "Muslims do not have positive attitudes towards Americans", “Muslims don't like Americans much", "Muslims don’t think of Americans in a friendly light", "Americans are not the favorite people of Muslims", "Muslims are very fond of Americans" (reverse-scored) and "Muslims feel warm toward Americans" (reverse-scored). The same scale anchors as for meta-dehumanization was used $(\alpha=.94)$.

\section{Results}


RUNNING HEAD: THEY SEE US AS LESS THAN HUMAN

Studies $1 \mathrm{a}$ and $1 \mathrm{~b}$ examined the effect of meta-dehumanization primes on dehumanization; here, we examined the opposite: whether increasing dehumanization of Muslims influenced participants' sense that Muslims dehumanized Americans. We found that participants primed to dehumanize Muslims did not report significantly higher levels of meta-dehumanization $(M=3.68, S D=1.43)$ than those in the control condition $(M=$ $3.43, S D=1.58 ; F(1,211)=1.53, p=.22$, partial $\left.\eta^{2}=.007\right)$. The same was true for meta-prejudice: participants primed to dehumanize Muslims showed slightly higher levels of meta-prejudice $(M=4.95, S D=1.19)$ than those in the control condition $(M=$ $4.70, S D=1.24)$, but this trend was not significant $\left(F(1,211)=2.26, p=.13\right.$, partial $\eta^{2}=$ $.01)$.

The results of Studies 1a-1c illustrate that whereas meta-dehumanization caused outgroup dehumanization, the reverse causal pathway_ examined using a very similar sample size and power to detect a comparable effect - was not reliable. Although the existence of the reverse causal pathway cannot be definitively ruled out on the basis of these studies (a point we develop further in the General Discussion), our results are more consistent with the notion that feeling dehumanized by another group induces dehumanization of that group, rather than the reverse.

In Studies 2-5b, we assessed individual variation in (measured) metadehumanization perceptions across a series of consequential real-world intergroup conflicts, examining how these perceptions might be uniquely associated with a range of hostile intergroup attitudes and behaviors via outgroup dehumanization.

\section{Study 2}


RUNNING HEAD: THEY SEE US AS LESS THAN HUMAN

In Study 2 we examined the relationship between Americans' metadehumanization with respect to Arabs, their dehumanization of Arabs, and measures such as torture support and support for drone strikes. Specifically, we examined whether any effects of meta-dehumanization on these variables might be explained in part by metadehumanization's effects on outgroup dehumanization. In order to ensure that any association between meta-dehumanization and intergroup outcomes was unique from any potential effects of political ideology, we controlled for a series of ideological variables - social dominance orientation, right-wing authoritarianism, and political conservatism - known to be strongly associated with aggressive intergroup outcomes generally, and dehumanization in particular (e.g., Kteily et al., 2012, 2014, 2015;

Leidner, Castano, Zaiser, \& Giner-Sorolla, 2010).

\section{Method}

Participants. American residents $(N=286)$ completed the study online through Amazon Mechanical Turk in February 2014. As in Studies 1a-c, we focused on the 271 native-born U.S. participants and further excluded one Arab-American participant ( $M$ age $=33.18, S D=11.78 ; 50.2 \%$ female; $80.3 \%$ White American; 5.2\% Black American; 4.8\% Asian American; 4.5\% Latino/Hispanic American; 3.3\% Biracial; 1.5\% Native American; 0.4\% Other).

Measures. The following constructs were assessed in fixed order.

Social dominance orientation. We used the 16-item SDO-6 scale (Pratto, Sidanius, Stallworth, \& Malle, 1994; $\alpha=.89$ ) to assess participants' support for hierarchy between groups. 
RUNNING HEAD: THEY SEE US AS LESS THAN HUMAN

Right-Wing authoritarianism. We used a 12-item version of the RWA scale (Altemeyer, 1988; $\alpha=.87$ ) to tap conventionality, submission to authority, and aggressiveness against norm violators.

Political conservatism. We assessed political conservatism with three items. Two items assessed the extent to which participants rated their social and economic views, respectively, on a continuum from 'Very Liberal' (0) to 'Very Conservative' (100). One item assessed political party preference on a scale from 0 ('Strong Democrat') to 100 ('Strong Republican'); $\alpha=.88$.

Meta-Dehumanization. We assessed meta-dehumanization with six items: "Arabs perceive Americans to be sub-human", "Arabs think of Americans as animal-like", "Arabs see Americans as less evolved than other groups", "Arabs think Americans are beasts", "Arabs consider Americans to belong to a lower form of civilization", and “Arabs think of Americans as vermin" $(\alpha=.97)$. All responses were made using unmarked sliders anchored at 0 ('Strongly Disagree') and 100 ('Strongly Agree’).

Dehumanization. We assessed dehumanization as in Study 1a, focusing on Ascent ratings of Arabs.

Emotional hostility. We assessed emotions towards Arabs by providing participants with seven emotions (anger, disgust, contempt, respect, and sympathy, fear, and envy), from which we used the first five emotions towards Arabs for our assessment of emotional hostility (respect and sympathy were reverse-scored; $\alpha=.80$ ).

Drone support. We assessed support for drone strikes using five items (e.g., "I support America's use of drone attacks against suspected militant targets in Yemen"; $\alpha=$ .87; see Kteily et al., 2014, 2015). 
RUNNING HEAD: THEY SEE US AS LESS THAN HUMAN

Surveillance of Arabs. Support for surveillance of Arabs was assessed using a 4item scale (sample item: "I think American intelligence services should place extra effort on the surveillance of Arab immigrants to the U.S."; $\alpha=.91$; see Supplemental Materials for full scale). All responses were made using unmarked sliders anchored at 0 ('Strongly Disagree') and 100 ('Strongly Agree’); the same scale was used for all other constructs assessed below (unless otherwise specified).

Arab distancing. We assessed Americans' support for distancing Arabs using six items tapping into a broad set of attitudes and social policies reflecting social rejection of Arabs and resistance to Arab integration into U.S. society (e.g., "It would bother me if my son or daughter ended up marrying an Arab"; "The U.S. government should set up programs to help Arab immigrants integrate into U.S. society (reverse-scored); $\alpha=.79$; see Supplementary Materials).

Opposition to Arab immigration. We assessed opposition to Arab immigration by asking participants to assign a limited number of immigrant visas to various groups (e.g., East Asians, Arabs, Eastern Europeans), and then taking the reverse-scored proportion of visas assigned to Arabs (Kteily et al., 2015).

Torture support. We assessed support for torture by averaging participant responses to five items taken from Kteily et al., 2014, 2015 (e.g., "To put an end to the war on terror in the Middle East, I think it is OK to use enhanced interrogation techniques; $\alpha=.91$; see Supplementary Materials).

We also included items about perceived American and Arab power, perceptions of American foreign policy, items assessing patriotism and nationalism, and items about 
RUNNING HEAD: THEY SEE US AS LESS THAN HUMAN

support for intervention in Syria for exploratory purposes. We did not use these variables for our primary analyses and they are not discussed further.

\section{Results}

Descriptive statistics and variable inter-correlations are presented in Table 1. As can be seen in the table, meta-dehumanization was significantly associated with dehumanization of Arabs, $r=.38, p<.001$. Moreover, both meta-dehumanization and Arab dehumanization were significantly correlated with each of the outcome measures.

We were primarily interested in examining whether meta-dehumanization was associated with anti-Arab attitudes and policy support through outgroup dehumanization. We included political ideology (i.e., each of SDO, RWA, and political conservatism) as control variables, and examined the full model using Hayes' (2013) PROCESS macro (Model 4), with 1,000 bootstrap resamples. We modeled each outcome measure separately (see Figure 3 for an example outcome, 'torture of Arabs').

In support of our predictions, the indirect effect from meta-dehumanization to anti-Arab attitudes and policy support through Arab dehumanization was significant for each of the criterion variables (see Table 2). Indeed, in line with the experimental manipulations in Studies 1a and 1b, meta-dehumanization was strongly associated with outgroup dehumanization $(\beta=.32, b=.30, p<.001,95 \% \text { CI }[.19, .41])^{10}$. Outgroup dehumanization was itself uniquely associated with each of the outcome variables (Surveillance of Arabs: $\beta=.24, b=.25, p<.001,95 \%$ CI $[.15, .35]$; Emotional Hostility: $\beta=.42, b=.32, p<.001,95 \%$ CI $[.25, .39]$; Torture support: $\beta=.16, b=.14, p=.004$, 95\% CI [.05, .24]; Drone support: $\beta=.14, b=.13, p=.004,95 \%$ CI [.04, .23]; Arab distancing: $\beta=.16, b=.13, p=.006,95 \%$ CI [.04, .22]; Opposition to Arab Immigration: 
RUNNING HEAD: THEY SEE US AS LESS THAN HUMAN

$\beta=.36, b=.09, p<.001,95 \%$ CI $[.06, .12])$.

After accounting for its indirect effects via dehumanization (as well as political ideology), meta-dehumanization had direct effects on each of the outcome variables, with the exception of opposition to immigration. Across all outcome measures, metadehumanization exhibited significant total effects. In sum, these data illustrate the potency of meta-dehumanization as a unique contributor to intergroup hostility, and demonstrate that a part of its role can be accounted for by its effect on outgroup dehumanization.

\section{Study 3}

In Study 3, we extended the examination of meta-dehumanization to a different cultural context, specifically Hungarians' responses to perceived dehumanization of the ingroup by the Roma population. Although the majority Hungarian population is advantaged relative to the minority Roma population, the discourse surrounding the Roma describes them as self-segregating from society and expressing disdain for the majority population by targeting them for theft and other 'parasitic' actions, implying a (perceived) disregard for the majority Hungarians and their suffering. Therefore, we reasoned that majority Hungarians could perceive that they themselves are dehumanized by the Roma, a perception we hypothesized would be associated with dehumanizing the Roma and aggressive intergroup attitudes. Study 3 also extended Study 2 by further controlling for outgroup prejudice in testing our theoretical model.

\section{Method}

Participants. We used a collection service (Solid Data SIA) to obtain a large sample online from Hungary in August 2014 for an omnibus study (we focus on the 
RUNNING HEAD: THEY SEE US AS LESS THAN HUMAN

variables relevant to the current work) ${ }^{11}$. The survey was translated into Hungarian by a native-speaking social psychologist. Of the 1,002 respondents, 12 were excluded for being Roma, and 84 for answering at least one of two attention check questions incorrectly, leaving 906 participants $(M$ age $=42.04, S D=12.75 ; 50.7 \%$ male $)$.

Measures. For all measures not already assessed on a 0-100 scale, scores were converted from their original scales (reported below) to a 0-100 scale for ease of comparison with previous studies. Variables were presented in fixed order.

Conservatism. Political conservatism was assessed using two items asking for self-placement on the left-right political spectrum $(1=$ Left; $7=$ Right $)$ and the liberalconservative $(1=$ Liberal; $7=$ Conservative $) \operatorname{spectrum}(r=.47, p<.001)$.

SDO-D. We assessed the dominance sub-dimension of the SDO scale $(\alpha=.86$; Ho et al., 2012; see also Ho et al., in press). Responses were made on scales anchored at 1 ('Strongly Disagree') and 6 ('Strongly Agree').

Prejudice. We assessed prejudice against the Roma similarly to prior studies, using feeling thermometer ratings towards the Roma on a scale anchored at 0 ('Cold, negative feelings') and 10 ('Warm, positive feelings'). Scores were reversed such that higher scores indicated greater outgroup prejudice.

Dehumanization. As in Studies 1 and 2, we assessed dehumanization using the Ascent scale. We assessed responses to a range of groups, including the Roma and ethnic Hungarians. Roma dehumanization was assessed by using ratings of Roma humanity on the Ascent measure, using a scale anchored at 0 (least 'evolved') and 10 (most 'evolved'). As in earlier studies, the scores were reversed such that higher scores indicate dehumanization. 
RUNNING HEAD: THEY SEE US AS LESS THAN HUMAN

Emotional hostility. We assessed hostile emotions towards the Roma by indexing each of the following emotions: anger, hatred, contempt, compassion (reverse-coded) and pity (reverse-coded); $\alpha=.83$. Responses were made on scales anchored at 1 ('Not at all') and 6 ('Very much so').

Funding to Roma integration. We assessed support for providing funding to Roma integration by asking participants to indicate the proportion of an EU fund they thought should be spent on "Roma integration and support" versus "Urban beautification" $(0=\text { 'None of the budget; } 100=\text { 'All of the budget' })^{12}$.

Support for discrimination. Support for discrimination was assessed using 14 items that indexed the extent to which individuals agreed with policies that discriminated against the Roma in domains spanning education, employment, and housing (e.g., "Decrease the number of Roma teachers"; "Cancel currently operating scholarships for Roma students"; see Supplementary Materials; $\alpha=.90)^{13}$. Responses were made on scales anchored at 1 ('Completely Disagree') and 6 ('Completely Agree'), and recoded such that higher scores indicated more discriminatory attitudes.

Perceptions of Roma homogeneity. We assessed perceptions of Roma homogeneity by asking participants to indicate how similar they thought the Roma are to each other across several dimensions (e.g., 'intellect', 'values', 'morality'; $\alpha=.91$; see Kteily et al., 2015). Responses were made on scales anchored at 1 ('Very different from one another') and 6 ('Very similar to one another').

Meta-dehumanization. Meta-dehumanization was assessed as in Study 1a ( $\alpha=$ .94), but with Roma as the target group. Scores were assessed on a 1-6 scale.

Responses to injustice. We assessed responses to injustices committed by the 
RUNNING HEAD: THEY SEE US AS LESS THAN HUMAN

ingroup towards the Roma by asking participants to read a real newspaper story about Hungarian hooligans who threatened and shouted vulgarities at Roma children and urinated around their school campus. We asked participants how angry, guilty and ashamed they felt as Hungarians, and how compassionate they felt towards the Roma children in response to the story $(\alpha=.86)$. Responses were made on scales anchored at 1 ('Not at all') and 6 ('Very much so').

\section{Results}

Descriptive statistics and variable inter-correlations are presented in Table 3. As in Study 2, perceived meta-dehumanization by the Roma was positively associated with dehumanization of the Roma, $r=.35, p<.001$. Meta-dehumanization was also associated with prejudice towards the Roma, $r=.35, p<.001$.

As with Study 2, in Study 3 we examined our proposed model using PROCESS (see Figure 4 for an example outcome, 'support for discrimination'). Specifically, we considered the extent to which meta-dehumanization was associated with hostile intergroup attitudes through dehumanization of the outgroup, controlling for political ideology (here, SDO and conservatism) throughout. We extended Study 2 by including prejudice (i.e., dislike) in the model. Meta-dehumanization was associated with greater outgroup dehumanization $(\beta=.19, b=.27, p<.001,95 \% \mathrm{CI}[.19, .35])$ and outgroup prejudice $(\beta=.22, b=.21, p<.001,95 \%$ CI $[.15, .26])$. Roma dehumanization was uniquely associated with each of the outcome measures (all $b s>.08, p \mathrm{~s}<.003$ ), with the exception of responses to injustice $(b=-.05, p=.10)$. Similarly, Roma prejudice was uniquely associated with each of the outcome measures (all $b s>.19$, ps $<.001$ ), with the exception of perceived homogeneity $(b=.04, p=.37)$. 
RUNNING HEAD: THEY SEE US AS LESS THAN HUMAN

We next examined the direct effects of meta-dehumanization on the outcome measures, and its indirect effects via each of dehumanization and prejudice (entered simultaneously as predictors; see Table 4). Consistent with the results of Study 2, metadehumanization had significant indirect effects, via dehumanization, on each of: reduced funding for Roma integration, support for discrimination against the Roma, perceptions of Roma homogeneity, and emotional hostility towards the Roma. Beyond these indirect effects via outgroup dehumanization, meta-dehumanization had significant indirect effects through the mediator of outgroup prejudice on funding to Roma integration, support for discrimination, less contrite responses to injustices committed towards the Roma, and emotional hostility towards the Roma. With the exception of responses to injustice and emotional hostility, meta-dehumanization had significant direct effects on each of the outcome measures after its relationships with outgroup dehumanization and outgroup prejudice were taken into account. Moreover, meta-dehumanization had significant total effects on all outcome measures.

In sum, among a large sample of ethnic Hungarians, the perception that the outgroup (i.e., Roma) dehumanizes the ingroup (i.e., majority Hungarians) was strongly associated with hostile outgroup perceptions and policy support. This was in part channeled through both dehumanization of and prejudice towards the 'offending' outgroup, even after controlling for political ideology. Consistent with the previous studies, these findings suggest the importance of meta-dehumanization as a predictor of hostile and aggressive intergroup perceptions, attitudes, and policy support.

\section{Study 4}

In Study 4, we sought to examine the role of meta-dehumanization in a highly 
RUNNING HEAD: THEY SEE US AS LESS THAN HUMAN

consequential social context involving very conflictual intergroup relations and a vicious ongoing cycle of intractable conflict (Bar-Tal, 2000): the Israeli-Palestinian conflict. Given the overt animosity frequently expressed and experienced in this context, we expected that meta-dehumanization would be highly associated with intergroup aggression. Another important goal of this study was to examine the uniqueness of metadehumanization as a meta-perception: specifically, we considered whether the perception that the ingroup is dehumanized by an outgroup contributes to the perpetuation of intergroup hostility beyond the perception that the ingroup is disliked by an outgroup (i.e., meta-prejudice).

\section{Method}

In May 2015, we collected data from 547 Israelis who responded to an online questionnaire about attitudes and perceptions towards Palestinians. We excluded 54 participants who answered at least one of two attention check questions incorrectly, resulting in a final sample of $493(M$ age $=40.96, S D=13.07 ; 52.9 \%$ male; $97.4 \%$ Jewish; $0.8 \%$ Christian; $0.4 \%$ Other; $1.4 \%$ No religion) ${ }^{14}$. In addition to the variables of interest, the questionnaire included an experimental manipulation and associated measures for purposes unrelated to the current study. ${ }^{15}$

Measures. All variables were assessed on scales anchored at 1 ('Strongly Disagree') and 7 ('Strongly agree'), but were converted to a 0-100 scale for ease of comparison across studies. Variables were presented in fixed order.

Emotional hostility. We assessed hostile emotions towards Palestinians by indexing each of the following emotions: hatred, anger, hostility, empathy (reversecoded), shame (reverse-coded), and guilt (reverse-coded; $\alpha=.76$ ). 
RUNNING HEAD: THEY SEE US AS LESS THAN HUMAN

Support for negotiations. Support for negotiation was assessed using two items: "How willing would you be for Israel to enter direct negotiations with the Palestinians?", and "Israel should make a concerted effort to negotiate a resolution with the Palestinians" $(r=.89, p<.001)$

Expulsion of Palestinians. We assessed support for the expulsion of Palestinians as a potential 'solution' to the Israeli-Palestinian conflict. Specifically, we asked participants to indicate their agreement with the following item: "Absorbing the West Bank and Gaza into Israel and forcing the Palestinians to go to Jordan". ${ }^{16}$

Support for aggressive Policies. We assessed support for aggressive policies towards the Palestinians, using seven items (e.g., "We should torture any Palestinian suspected of building tunnels in Gaza"; "Israel should use live fire to disperse Palestinian protests, even at the cost of hurting civilians and bystanders"; $\alpha=.84$; see Supplementary Materials).

Meta-dehumanization. Meta-dehumanization was assessed using the same 5 items as in Study $3(\alpha=.92)$, here with respect to Palestinians.

Meta-prejudice. Meta-prejudice was assessed using the following two items: "Palestinians feel cold towards Israelis", and "Palestinians do not hold positive attitudes towards Israelis" $(r=.63, p<.001)$.

Dehumanization. Dehumanization was assessed using the Ascent scale of blatant dehumanization, assessed with respect to a number of groups, including Palestinians and Israelis. We assessed outgroup dehumanization as in previous studies, by reverse scoring ratings of Palestinians.

\section{Results}


RUNNING HEAD: THEY SEE US AS LESS THAN HUMAN

Descriptive statistics and variable inter-correlations can be found in Table 5. We began by exploring the dimensionality of the items assessing meta-dehumanization and meta-prejudice. Submitting these seven items to a principal component factor analysis with oblique rotation yielded two distinct factors. Consistent with our theorizing, the first factor (eigenvalue $=4.34,62.04 \%$ variance explained) reflected meta-dehumanization (all factor pattern loadings $>.74$ ), and the second factor (eigenvalue $=1.17,16.68 \%$ variance explained) reflected meta-prejudice (factor pattern loadings $>.85$ ). There were no crossloadings across factors (i.e., no variable had a factor pattern loading $>.30$ on the other factor). We created two composites, one for each of these constructs (meta-prejudice: $M$ $=72.32, S D=25.31$; meta-dehumanization: $M=41.34, S D=28.00)$, which were intercorrelated, $r=.48, p<.001$.

We next examined the relationship between meta-dehumanization, metaprejudice, and dehumanization of Palestinians. Both meta-dehumanization $(r=.30, p<$ $.001)$ and meta-prejudice $(r=.25, p<.001)$ were associated with greater dehumanization of Palestinians. When we entered these two variables into a simultaneous regression predicting dehumanization, each explained unique variance (meta-dehumanization: $\beta=$ $.23, b=.22, p<.001,95 \%$ CI $[.12, .32]$; meta-prejudice: $\beta=.15, b=.16, p=.003,95 \%$ CI $[.05, .26])$.

We next examined the indirect effects of meta-dehumanization on the outcome variables via dehumanization of Palestinians, as well as its direct and total effects. As can be seen in Table 6, meta-dehumanization had a significant indirect effect on all outcome variables via outgroup dehumanization, controlling for meta-prejudice (see Figure 5 for an example outcome, 'support for aggressive policies'). Meta-dehumanization further had 
RUNNING HEAD: THEY SEE US AS LESS THAN HUMAN

significant direct and total effects on all variables, again suggesting its unique role in predicting hostile intergroup attitudes and policies. In parallel to meta-dehumanization, meta-prejudice was also uniquely associated with several of the outcome variables (see Supplementary Table 1).

Study 4 extended our research in several important ways: First, it documented the importance of meta-dehumanization in another national context marked by hostile intergroup relations. Second, it showed this consistently across a range of highly meaningful and consequential outcome measures, including efforts for peaceful conflict resolution (i.e., support for negotiation) as well as highly belligerent actions, such as population transfer and support for collective aggression, likely to contribute to an ongoing cycle of conflict. Finally, and importantly, we established that perceiving that another group dehumanizes the ingroup is distinct from perceiving that they dislike the ingroup. Interestingly, this meta-perceptual distinction between being (perceived to be) dehumanized and disliked parallels a similar distinction between dehumanizing and disliking, which have been shown to exert independent effects on intergroup outcomes (e.g., Andrighetto et al., 2014; Kteily et al., 2015).

In Studies 5a and 5b, we sought to further our research in two primary ways. First, we aimed to re-examine the unique effects of meta-dehumanization and meta-prejudice while simultaneously examining both outgroup dehumanization and outgroup prejudice. This allowed us to test an important and heretofore unanswered question: whether there is a dehumanization-specific pathway — from meta-dehumanization through dehumanization to aggressive intergroup attitudes and policy support — that is independent of both meta-prejudice and prejudice (as per Figure 1). Second, in addition 
RUNNING HEAD: THEY SEE US AS LESS THAN HUMAN

to attitudes and policy support, we included behavioral criterion measures.

Study 5a focused on Americans' perceptions and meta-perceptions with respect to ISIS members. This study was conducted shortly after the attacks in Paris, France in January 2015 in which Muslim extremists associated with ISIS killed 11 individuals at the satirical magazine Charlie Hebdo, following the publication of what were perceived as demeaning and highly offensive images of the prophet Mohammed. Study $5 \mathrm{~b}$ examined Americans' perceptions and meta-perceptions with respect to Iran in the summer of 2015, shortly after the Iran nuclear deal was announced and while its benefits and risks were being hotly debated.

\section{Study 5a}

\section{Method}

Participants. We collected data from 423 participants on Amazon’s mTurk platform a few days after the Charlie Hebdo attacks in January 2015. We excluded one Arab participant and 56 non-native born participants, leaving 366 participants $(M$ age $=$ 32.72, $S D=11.01 ; 57.9 \%$ female; $83.1 \%$ White American, 4.9\% Asian American, 4.4\% Black American; 4.6\% Latino/Hispanic American; 1.9\% Biracial; 0.8\% Native American; 0.3\% Other).

Measures. We began by assessing meta-dehumanization and meta-prejudice, which were presented in randomized order.

Meta-dehumanization. Meta-dehumanization was assessed (with respect to how ISIS perceive Westerners), using the same six-item scale as in Study $2(\alpha=.88)$. We focused here on meta-perceptions relating to Westerners given that the Charlie Hebdo attacks occurred in France (rather than the U.S.), and reflected a larger conflict between 
RUNNING HEAD: THEY SEE US AS LESS THAN HUMAN

ISIS and Western nations (and values). We reasoned that in this context, Americans' membership in the broader category of 'Westerner' would be most relevant with respect to their meta-perceptions.

Meta-prejudice. Meta-prejudice was assessed (with respect to how ISIS perceive Westerners) using the two-item scale in Study $4(r=.71, p<.001)$.

Next participants reported their dehumanization and prejudice towards ISIS.

Dehumanization. Dehumanization of ISIS was assessed as in previous studies (i.e., by taking the reverse score of the humanity attributed to ISIS on the 0-100 Ascent scale of blatant dehumanization).

Prejudice. Prejudice towards ISIS was assessed using reverse scored ratings of ISIS on the feeling thermometer, as in Study 3 (on a 0-100 scale).

We next assessed a range of outgroup attitudes and behavior. Variables were presented in randomized order. ${ }^{17}$

Drone support. Support for drone strikes was assessed using the same five-item scale as in Study 2, with slight modifications (e.g., "I support Western countries using drone attacks against suspected militant targets in Yemen"; $\alpha=.84$ ).

Opposition to Muslim immigration. Opposition to Muslim immigration to the U.S. was assessed as in Study 2.

Militaristic counter-terrorism. Support for militaristic counter-terrorism was assessed using a 13-item scale adapted from Kteily et al. (2014, 2015; e.g., "To put an end to terrorist acts by ISIS, I think it is OK to use enhanced interrogation techniques"; "We should strike back with brutal force against any members of ISIS who seek to intimidate us"; $\alpha=.93$; see Supplementary Materials). Responses were made on scales 
RUNNING HEAD: THEY SEE US AS LESS THAN HUMAN

anchored at 1 ('Strongly Disagree') and 7 ('Strongly Agree'), and then converted to a 0100 scale.

Signing anti-ISIS petitions. We examined whether participants chose to sign in support or opposition of six different petitions, taken from Kteily et al. (2015, Study 5), about taking various measures to combat ISIS (e.g., "Increase the military budget allotted to combating the ISIS threat"; "Forcibly deport all Islamic clerics in the U.S. who preach in favor of ISIS." Participants were told that the petition sponsors had agreed to use mTurk IDs as proxies for names because they are uniquely assigned to individuals. For each petition, participants could indicate whether they would like to add their mTurk ID in support (coded as +100 ), in opposition (coded as -100 ), or choose not to add their mTurk ID at all (coded as 0). Responses were coded such that higher scores reflected more hostility towards ISIS $(\alpha=.78)$.

Anti-Islamic extremism fund disbursement. We assessed anti-Islamic extremism fund disbursement by asking participants to distribute funds between two programs aimed at decreasing extremism among Islamic communities in the U.S.: one centered on policing and surveillance of Muslims, and the other on providing them with education and opportunities for learning (see Kteily et al., 2015, Study 5). We used the percentage of funds allocated to policing and surveillance of Muslims as our measure of punitiveness.

Encouragement of U.S. troops fighting ISIS. We gave participants the opportunity to write messages in support of American troops combatting ISIS: we assigned a score of 100 to participants who chose to write a message, and a score of 0 to those who did not (Kteily et al., 2015, Study 5). 
RUNNING HEAD: THEY SEE US AS LESS THAN HUMAN

Supportive Messages to Families of Hebdo Victims. Subsequent to being given the opportunity to write in support of U.S. troops, participants received the same prompt about whether or not they would like to write a message in "support of the families of the French journalists at Charlie Hebdo targeted in the past several hours". We assigned a score of 100 to participants who chose to write a message, and a score of 0 to those who did not. ${ }^{18}$

Punitiveness towards Hebdo Attackers. After selecting whether or not they wanted to write a message to the families of the victims of the Charlie Hebdo attacks, we also asked participants to report their agreement with each of the following items assessing punitiveness towards the perpetrators (Kteily et al., 2014): “The perpetrators of the Charlie Hebdo attacks deserve to die a slow, painful death", "If found guilty of the attack, the perpetrators of the Charlie Hebdo attack should be subjected to the death penalty", and "I hope the perpetrators of the Charlie Hebdo attack rot in hell" $(\alpha=.80)$. Responses were made on scales anchored at 1 ('Strongly Disagree') and 7 ('Strongly Agree'), and transformed to a 0-100 scale, with higher scores indicate greater agreement for ease of comparison with previous studies.

Conservatism. We assessed conservatism with 3 items as in Study $2(\alpha=.89)$.

\section{Results}

Descriptive statistics and variable inter-correlations can be found in Table 7. We submitted the eight items assessing meta-dehumanization and meta-prejudice to a principal components analysis with oblique rotation. Consistent with Study 4, two factors emerged: the first factor (eigenvalue $=3.56,50.84 \%$ variance explained) reflected metadehumanization (all factor pattern loadings $>.70$ ), and the second factor (eigenvalue $=$ 
RUNNING HEAD: THEY SEE US AS LESS THAN HUMAN

$1.33,19.01 \%$ variance explained, all factor pattern loadings $>.90)$ reflected metaprejudice. Using a factor loading of .30 as a cutoff, there were once more no crossloadings across the two factors, which were correlated at $r=.38, p<.001$.

In our main analysis, we tested our full theoretical model (see Figure 1): we examined whether meta-dehumanization was uniquely associated with the outcome measures via dehumanization, controlling for both meta-prejudice and outgroup prejudice (as well as conservatism). That is, we sought to identify, for the first time, a dehumanization-specific pathway from meta-perceptions to outgroup attitudes and policy support.

The first part of our model (i.e., 'a' path in Figure 1) links meta-dehumanization to outgroup dehumanization. As expected, meta-dehumanization $(r=.26, p<.001)$, but not meta-prejudice $(r=.04, p=.47)$, was significantly correlated with dehumanization of ISIS. We observed this same pattern when we entered these two variables into a simultaneous regression (controlling for conservatism): meta-dehumanization predicted dehumanization of ISIS ( $\beta=.29, b=.50, p<.001,95 \%$ CI $[.31, .68])$, whereas metaprejudice did not $(\beta=-.07, b=-.16, p=.19,95 \%$ CI $[-.38, .08])$. Beyond its association with outgroup dehumanization, we also observed that meta-dehumanization was associated with anti-ISIS prejudice $(r=.33, p<.001)$, as was meta-prejudice $(r=.38, p<$ .001). When simultaneously entered into a regression, both variables predicted unique variance in anti-ISIS prejudice (meta-dehumanization: $\beta=.21, b=.24, p<.001,95 \% \mathrm{CI}$ $[.11, .38]$; meta-prejudice: $\beta=.30, b=.42, p<.001,95 \%$ CI $[.23, .64]$.

The second part of our model (i.e., 'b' path in Figure 1) posits that dehumanization will be uniquely associated with outcome measures, independent of 
RUNNING HEAD: THEY SEE US AS LESS THAN HUMAN

outgroup prejudice (and all other predictors; i.e., meta-dehumanization, meta-prejudice, and conservatism). With the exception of sending messages of support to American troops fighting ISIS $(b=.01, p=.07,95 \% \mathrm{CI}[-.00, .02])$ and messages of support to the families of the Hebdo attack victims $(b=.001, p=.73,95 \%$ CI $[-.01, .01])$, dehumanization of ISIS was itself uniquely associated with each of the outcome variables (all $b s>.05$, all $p s<.045$ ). Beyond the role of dehumanization, prejudice towards ISIS itself was significantly associated with punitiveness towards the Hebdo attackers $(\beta=.19$, $b=.27, p=.001,95 \%$ CI $[.11, .44]$, support for punishing and controlling (vs. educating) Muslims to prevent extremism $(\beta=.13, b=.18, p=.02,95 \%$ CI $[.04, .33])$, signing antiISIS petitions $(b=.17, p=.04,95 \%$ CI $[.01, .33])$, militaristic counter-terrorism $(\beta=.20$, $b=.21, p<.001,95 \%$ CI $[.11, .30])$, and drone strike support $(\beta=.21, b=.22, p<.001$ $95 \%$ CI $[.11, .33])$.

Finally, our model posits that meta-dehumanization will be associated with intergroup outcomes in part via its effects on outgroup dehumanization. As in prior studies we examined the indirect, direct, and total effects of meta-dehumanization on the outcome variables, controlling for ideology (here, conservatism; see Figure 6 for an example outcome, 'signing anti-ISIS petitions'). We began by focusing on the pathway of particular interest: from meta-dehumanization to the outcome variables via dehumanization of ISIS. Consistent with predictions, this indirect pathway was significant for drone support, militaristic counter-terrorism, opposition to immigration, signing anti-ISIS petitions, distributing funds to the control and punishment of Muslims (vs. educating them), and punitiveness towards the Hebdo attackers (but not for sending messages to U.S. troops fighting ISIS or families of the Hebdo victims; see Table 8). 
RUNNING HEAD: THEY SEE US AS LESS THAN HUMAN

Meta-dehumanization also had significant indirect effects on six of the eight outcome measures via prejudice towards ISIS. In fact, meta-dehumanization was associated with intergroup attitudes and behavior in this study largely through its indirect effects: once these were accounted for, it had significant direct effects only on signing anti-ISIS petitions and punitiveness towards the Hebdo attackers. Exploring the total effects, there was evidence of meta-dehumanization contributing uniquely to the explanation of militaristic counter-terrorism, opposition to immigration, signing anti-ISIS petitions, and punitiveness towards the Hebdo attackers.

We observed less evidence, on the other hand, for unique effects of metaprejudice on the outcome measures (see Supplementary Table 2). There was some support for a prejudice-specific pathway from meta-perceptions to outcomes: metaprejudice had significant indirect effects via prejudice on five of the outcome measures. On the other hand, it exhibited no indirect effects via dehumanization, and had no significant direct effects on any of the outcome variables. When total effects were examined, there was no evidence that meta-prejudice provided additional utility in predicting the outcome variables in this context.

In sum, the results of Study 5a provide further evidence for the unique role of meta-dehumanization in intergroup conflict settings. Among a large community sample of Americans, and specifically focusing on meta-perceptions regarding ISIS (the group widely thought to be associated with the Charlie Hebdo attacks), we observed that: (a) meta-dehumanization is distinct from meta-prejudice; (b) meta-dehumanization is associated with intergroup outcomes via outgroup dehumanization, independent of prejudice and political ideology; and (c) meta-dehumanization is associated not only with 
RUNNING HEAD: THEY SEE US AS LESS THAN HUMAN

intergroup attitudes, but also with behavior.

In Study 5b, we re-examined the role of meta-dehumanization and meta-prejudice among Americans in a separate context and focusing on a different outgroup.

Specifically, we assessed meta-perceptions relating to Iran shortly after the announcement of the hotly debated nuclear deal that President Obama announced in July

2015. We also expanded our measurement of meta-prejudice (i.e., using a 5-item scale, as in Study 1b) and of blatant dehumanization (including, as in Study 1b, outgroup ratings a series of blatant animalistic traits in addition to Ascent scale ratings).

\section{Study 5b}

Participants. We collected data from 312 U.S. residents on Amazon's mTurk platform in July 2015. We excluded one Arab participant and one who did not report ethnicity, leaving 310 participants $(M$ age $=31.80, S D=9.86 ; 53.6 \%$ female; $79.7 \%$ White American; 8.1\% Hispanic American; 5.8\% African American; 3.9\% Asian American; 1.9\% Native American; 0.6\% Other).

\section{Measures.}

Conservatism. Conservatism was assessed using two items assessing selfplacement on 1 ('Very liberal') to 7 ('Very conservative') scales assessing economic and social conservatism, respectively. Scores were transformed to a $0-100$ scale $(r=.52, p<$ $.001)$.

Next, participants responded to items about prejudice and dehumanization, in randomized order.

Prejudice. Prejudice towards Iranians was assessed using reverse scored ratings of Iranians on the feeling thermometer, as in previous studies (on a 0-100 scale). 
RUNNING HEAD: THEY SEE US AS LESS THAN HUMAN

Dehumanization. As in Study 1b, we computed a dehumanization composite by taking the average of (a) reverse-scored ratings of Iranians on the Ascent scale (as in previous studies reported here; $M=22.53, S D=25.48$ ) and (b) ratings of Iranians on a series of nine animalistic traits adapted from Bastian et al. (2013); e.g., "savage, aggressive", "barbaric, cold-hearted”, “capable of self control” (reverse-scored), and "rational and logical" (reverse-scored). Participants rated the extent to which these traits descried Iranians on a 1 ('Not at all') to 7 ('Extremely so') scale $(\alpha=.90 ; M=4.01, S D=$ 1.20). ${ }^{19,20}$ Ascent dehumanization scores and animalistic trait ratings were highly correlated $(r=.57, p<.001)$, and they were thus standardized and averaged to comprise a blatant dehumanization composite.

Meta-dehumanization. Meta-dehumanization was assessed (with respect to how Iranians perceive Americans) using the same six-item scale as in Study 2, with the last item from that scale (referring to 'vermin') replaced with "Iranians would happily step on Americans like cockroaches" $(\alpha=.95)$.

Meta-prejudice. Meta-prejudice was assessed using the following items: "Iranians feels cold towards Americans", "Iranians do not have positive attitudes towards Americans", “Iranians don’t like Americans much", “Iranians don't think of Americans in a friendly light", and “Americans are not Iranians' favorite people” $(\alpha=.97)$.

We next assessed a range of outgroup attitudes and behavior, presented in fixed order:

Opposition to the Iran Nuclear Deal was assessed by asking participants to indicate their agreement or disagreement with six statements on a scale anchored at 1 (Strongly Disagree) and 7 (Strongly Agree): "I am embarrassed that the U.S. negotiated 
RUNNING HEAD: THEY SEE US AS LESS THAN HUMAN

with the Iranians rather than enforcing our will militarily", "Iran is dedicated to the destruction of the U.S.", "The Iranians will use the money we give them to buy conventional weapons, and the moment they get a chance, they will build a nuclear weapon", "This treaty has the potential to heal old wounds between the U.S. and Iran, and bring our two countries closer together" (reverse-scored), "I am in favor of the U.S. nuclear deal with Iran" (reverse-coded), and "I think Iran is just as entitled to a nuclear program as any other nation." (reverse-scored; $\alpha=.87)^{21}$. We transformed scores to a 0 100 scale for ease of comparison.

Aggressive Actions towards Iranians was assessed by asking participants to indicate their agreement or disagreement with each of twelve actions towards Iranians (e.g., "I think it's acceptable to assassinate Iranian nuclear scientists", "Anyone caught in America spying on the U.S. for Iran should be sentenced to prison for life without parole"; see Supplemental Materials for full scale). Items were assessed on a scale anchored at 1 ('Strongly Disagree') and 7 ('Strongly Agree'), and scores were transformed to a $0-100$ scale $(\alpha=.93)$.

Signing Anti-Nuclear Deal Petitions. Using the same methodology as in Study 5a, we assessed whether participants chose to sign in support or opposition to five different petitions relating to the Iran nuclear deal (e.g., "Urge congressional members to examine military options against Iran"; $\alpha=.85$; see Supplemental Materials for full scale).

We also included items outside the scope of the current study (e.g., items on intergroup contact), which were not used and are not discussed further.

\section{Results}


RUNNING HEAD: THEY SEE US AS LESS THAN HUMAN

Descriptive statistics and variable inter-correlations can be found in Table 9. We submitted the items assessing meta-dehumanization and meta-prejudice to a principal components analysis with oblique rotation. Consistent with Studies 4 and 5a, two factors emerged: the first factor (eigenvalue $=71.44,71.44 \%$ variance explained) reflected metadehumanization (all factor pattern loadings $>.74$ ), and the second factor (eigenvalue $=$ $1.45,13.15 \%$ variance explained, all factor pattern loadings $>.86)$ reflected metaprejudice. Using a factor loading of .30 as a cutoff, there were once more no crossloadings across the two factors. The meta-dehumanization and meta-prejudice composites were correlated at $r=.70$.

We examined our full theoretical model as in Study 5a. Meta-dehumanization $(r$ $=.64, p<.001)$ and meta-prejudice $(r=.50, p<.001)$ were both significantly correlated with dehumanization of Iranians. Replicating the results of Study 5a, when we entered these two variables into a simultaneous regression (controlling for conservatism), metadehumanization was uniquely associated with dehumanization of Iranians $(\beta=.55, b=$ $.02, p<.001,95 \%$ CI $[.01, .02])$, whereas meta-prejudice was not $(\beta=.09, b=.00, p=$ $.15,95 \%$ CI $[-.00, .01])$. Beyond outgroup dehumanization, meta-dehumanization $(r=$ $.48, p<.001)$ and meta-prejudice $(r=.46, p<.001)$ were each correlated with anti-Iran prejudice. Consistent with Study 5a, when simultaneously entered into a regression, both variables were uniquely associated with anti-Iran prejudice (meta-dehumanization: $\beta=$ $.28, b=.30, p<.001,95 \%$ CI $[.15, .45]$; meta-prejudice: $\beta=.23, b=.25, p=.001,95 \%$ CI $[.10, .41])$, controlling for conservatism.

Next, we examined the effects of dehumanization on the outcome measures. Consistent with our theoretical model, outgroup dehumanization predicted all of the 
RUNNING HEAD: THEY SEE US AS LESS THAN HUMAN

outcome variables, controlling for all other predictors (i.e., meta-dehumanization, metaprejudice, outgroup prejudice, and conservatism): opposition to the Iran nuclear deal ( $\beta=$ $.32, b=8.42, p<.001,95 \%$ CI $[4.52,12.21])$, aggressive actions towards Iranians $(\beta=$ $.30, b=7.52, p<.001,95 \% \mathrm{CI}[3.91,11.13])$, and signing petitions against the nuclear $\operatorname{deal}(\beta=.16, b=7.19, p=.04,95 \% \mathrm{CI}[.77,13.64])$. In contrast to dehumanization, although prejudice towards Iran significantly predicted aggressive actions $(\beta=.13, b=$ $.09, p=.02,95 \%$ CI $[.004, .18])$, it was not uniquely associated with opposition to the Iran nuclear deal $(\beta=.00, b=.00, p=.97,95 \%$ CI $[-.09, .10])$ or signing petitions against the nuclear deal $(\beta=.00, b=.00, p=1.00,95 \%$ CI $[-.17, .17]$.

Finally, we examined whether the dehumanization-specific indirect pathway from meta-perceptions to outgroup attitudes and behavior held as in Study 5a. We examined the indirect, direct, and total effects of meta-dehumanization on the outcome variables, controlling for ideology (here, conservatism; see Figure 7 for an example outcome, 'aggressive actions towards Iran'). As with Study 5a, the indirect pathway from metadehumanization to outcomes via outgroup dehumanization was significant across outcome measures, including our behavioral measure of signing anti-Nuclear deal petitions (see Table 10). In addition to its indirect effects via outgroup dehumanization, meta-dehumanization also had indirect effects on aggressive actions towards Iranians via outgroup prejudice (but not for the other outcome measures). Beyond these indirect effects, meta-dehumanization's direct and total effects were significant across the outcome measures.

Also consistent with Study 5a, meta-prejudice exhibited less of a unique association with the outcome measures (see Supplementary Table 3). There was some 
RUNNING HEAD: THEY SEE US AS LESS THAN HUMAN

support for a prejudice-specific pathway: there were significant indirect effects from meta-prejudice on aggressive actions towards Iranians (though not for the other two outcome measures) through outgroup prejudice. On the other hand, meta-prejudice had no indirect effects via dehumanization, and exhibited no significant direct or total effects on any of the outcome variables.

In sum, the results of Study $5 \mathrm{~b}$ replicate the results of Study 5a, and provide further evidence for the unique role of meta-dehumanization in intergroup conflict settings. Among a large community sample of Americans, and focusing on metaperceptions regarding Iranians during a period where the intergroup relationship between the two sides came under close scrutiny, we again observed that: (a) metadehumanization is distinct from meta-prejudice, (b) meta-dehumanization is associated with intergroup outcomes via outgroup dehumanization, independent of prejudice and political ideology, and (c) meta-dehumanization is associated not only with intergroup attitudes, but also with behavior.

The set of studies described thus far have documented, for the first time, that perceiving that one's own group is blatantly dehumanized by an outgroup increases blatant dehumanization of that group in turn. These studies have also provided further empirical support for the notion that blatant outgroup dehumanization itself contributes to a range of aggressive outcomes that may foment cycles of intergroup conflict and violence. If perceiving that another group dehumanizes the ingroup increases outgroup dehumanization, thereby helping to ignite a process contributing to intergroup strife, might providing information that the outgroup humanizes the ingroup serve as an effective intervention to reduce outgroup dehumanization? We examined this question in 
RUNNING HEAD: THEY SEE US AS LESS THAN HUMAN

Study 6 .

\section{Study 6}

In Studies 1a and 1b, we established that priming Arab meta-dehumanization of Americans resulted in the reciprocal dehumanization of Arabs. In Study 6, we examined whether priming meta-humanization could similarly humanize a typically dehumanized target group?

\section{Method}

Participants. We collected data from 220 participants through Amazon Mechanical Turk in October 2015 22. Data from three Muslim participants, four participants non-native to the U.S. and two participants who asked that their data be excluded from the study were removed from analysis, leaving 211 participants $(M$ age $=$ 36.77, $S D=12.85 ; 50.7 \%$ male; $80.1 \%$ White American; 7.6\% Asian American; 5.7\% African American; 3.8\% Hispanic American; 1.9\% Biracial; 0.9\% Other).

Procedure. Participants followed the same general procedure as in Study 1b: in the experimental condition, participants read an article purportedly published in the Boston Globe describing the results of a report by the United Nations' Commission on Global Relations examining public perceptions of Americans in the Muslim world. The article was entitled "In large parts of Muslim world, American achievements greatly admired" (see Supplementary Materials for full text). The article was modeled closely after that used in Study 1b, but described Muslims' perceptions of Americans in humanizing (rather than dehumanizing) terms, such as "technologically advanced", "sophisticated", "culturally advanced", and as having "enlightened" principles. The article also quoted Muslims respondents extolling the American educational system, and 
RUNNING HEAD: THEY SEE US AS LESS THAN HUMAN

U.S. efforts to avoid civilian casualties during wartime. As in Study 1b, the report noted that these perceptions of Americans were highly normative, held by a majority of Muslims. ${ }^{23}$ We examined the effect of this meta-humanizing prime on Muslim dehumanization and prejudice, presented in random order.

\section{Outcome Measures.}

Dehumanization. As in previous studies, participants rated a number of groups, including Muslims and Americans, on the Ascent scale. We assessed participants' dehumanization of Muslims, as in Study 1b, using both the (reverse-scored) Ascent scale rating of Muslims $(M=25.01, S D=29.49)$, and ratings of Muslims on the animalistic traits adapted from Bastian et al. $(2013 ; \alpha=.96 ; M=3.69, S D=1.35)$. We again also examined blatant dehumanization as a composite by standardizing the two dehumanization scores (i.e., Ascent and the animalistic trait composite) and averaging them together $(r=.59, p<.001)$.

Prejudice. We assessed prejudice towards Muslims as in Study 1b, using reverse-scored feeling thermometer ratings of Muslims $(M=54.84, S D=30.46)$.

\section{Results}

In our primary analyses, we examined whether the experimental manipulation influenced participants' dehumanization of, and prejudice towards, Muslims. We began by examining the (standardized) blatant dehumanization composite. As predicted, Americans who read the article suggesting that Muslims humanized Americans were significantly less likely to dehumanize Muslims $(M=-.18, S D=.78)$ than participants in the control condition $(M=.18, S D=.96), F(1,208)=7.11, p=.004$, partial $\eta^{2}=.04$. We also examined each of the dehumanization scales separately. Ascent dehumanization was 
RUNNING HEAD: THEY SEE US AS LESS THAN HUMAN

significantly lower in the meta-humanization condition $(M=19.89, S D=24.34)$ than it was in the control condition $\left(M=30.09, S D=33.17 ; F(1,209)=6.49, p=.01\right.$, partial $\eta^{2}$ $=.03){ }^{24,25,26}$ Similarly, animalistic trait ratings of Muslims were also lower in the metahumanization condition $(M=3.44, S D=1.29)$ relative to the control condition $(M=3.93$, $S D=1.36 ; F(1,209)=7.10, p=.008$, partial $\left.\eta^{2}=.03\right)$.

In contrast to dehumanization, prejudice towards Muslims was similar in the meta-humanization condition $(M=42.37, S D=28.77)$ and the control condition $(M=$ 47.92, $S D=31.95 ; F(1,209)=1.76, p=.19$, partial $\left.\eta^{2}=.01\right)$.

Thus, these results demonstrated that individuals who learn that the outgroup perceives them in humanizing ways in turn humanize the outgroup. In this way, metahumanization may serve as an effective intervention in decreasing the tendency to dehumanize outgroups.

Studies 1-6 support the notion that (meta-)perceptions about the extent to which the ingroup is seen as human influence individuals' own attributions of outgroup humanity (with implications for intergroup outcomes), but do not directly provide empirical support for the mechanisms that we posit to underlie this association. In Study 7, we tested the proposed mediating role of identity threat and desires for reciprocity.

\section{Study 7}

In the introduction, we reasoned that perceiving that the ingroup is dehumanized by an outgroup would provoke social identity threat (Branscombe et al., 1999a), generating a desire to reciprocate that hostility towards the offending outgroup (Bourhis et al., 1979; Doosje \& A. Haslam, 2005). Here, we examined whether individuals learned that they were dehumanized (vs. humanized) by an outgroup would be more likely to feel 
RUNNING HEAD: THEY SEE US AS LESS THAN HUMAN

identity threat and a desire to reciprocate the outgroup's perception, which might account for individuals' own ratings of the outgroup's humanity.

\section{Method}

Participants. We collected data from 259 participants through Amazon Mechanical Turk in October 2015. Data from one Muslim participant, nine participants non-native to the U.S. and one participant who asked for data exclusion were removed from analysis; an additional sixteen subjects failed one of the attention check questions (see below), leaving 231 participants $(M$ age $=36.51, S D=11.86 ; 52.8 \%$ female; $82.3 \%$ White American; 6.5\% African American; 4.8\% Hispanic American; 3.0\% Asian American; 1.3\% Native American; 1.3\% Biracial; 0.4\% Arab American; 0.4\% Other).

Procedure. Participants followed the same procedure as in Study 6, with the exception that participants were randomly assigned to receive either the metadehumanization prime (from Study 1b) or the meta-humanization prime (from Study 6). After reading the primes, participants were asked to respond to items assessing their sense of threat and desire to reciprocate Muslims' perceptions of Americans, before being presented with items assessing dehumanization. We further used two attention checks at the end of the study, asking participants to report (a) whether the article they read suggested that Muslims had a positive, negative, or undetermined view of Americans, and (b) correctly recall the organization that authored the report detailed in the newspaper article. $^{27}$

Measures.

Identity threat. We assessed participants' sense of threat to their American identity by asking them to answer the following items, all preceded by the stem, "When I 
RUNNING HEAD: THEY SEE US AS LESS THAN HUMAN

think about the way that Muslims perceive Americans": "I find it offensive", "I find it illegitimate", "I find it threatening", "I think it is reasonable" (reverse-coded), and "I find it appropriate" (reverse-coded). Participants responded on a scale anchored at 1 ("Not at all') and 7 ('Very much so'; $\alpha=.86)$.

Reciprocity. We assessed participants' desire to reciprocate Muslims' perceptions of Americans by asking them to indicate their agreement with each of the following items (preceded by the same stem as above): "It makes me want to respond back negatively", and "It makes me want to respond back positively" (reverse-coded). Participants again responded on a scale anchored at 1 ('Not at all') and 7 ('Very much so'; $r=.58, p<$ $.001) .^{28}$

Dehumanization. As in Study 6, dehumanization of Muslims was assessed by Ascent dehumanization, animalistic trait ratings, and their composite $(r=.56, p<.001)$.

\section{Results}

We first examined the effect of experimental condition on each of the proposed mediators. Participants in the meta-dehumanization condition reported higher levels of identity threat $(M=4.22, S D=1.39)$ than those in the meta-humanization condition $(M=$ $2.50, S D=.99 ; F(1,229)=115.46, p<.001$, partial $\left.\eta^{2}=.34\right)$. Similarly, participants in the meta-dehumanization condition reported a higher desire to reciprocate hostility $(M=$ $3.84, S D=1.66)$ than those in the meta-humanization condition $(M=2.30, S D=1.12 ; F$ $(1,229)=67.54, p<.001$, partial $\left.\eta^{2}=.23\right)$. These two mediators were themselves quite correlated, $r=.71, p<.001$.

We next examined the effect of experimental condition on outgroup dehumanization. We observed that those in the meta-dehumanization condition indicated 
RUNNING HEAD: THEY SEE US AS LESS THAN HUMAN

higher levels of outgroup dehumanization on the composite dehumanization measure ( $M$ $=.21, S D=.96)$ than those in the meta-humanization condition $(M=-.23, S D=.73 ; F(1$, $229)=15.04, p<.001$, partial $\left.\eta^{2}=.06\right)$. We observed similar results for the individual scales: participants in the meta-dehumanization condition indicated greater Ascent dehumanization $(M=27.22, S D=32.57)$ than those in the meta-humanization condition $\left(M=15.27, S D=21.71 ; F(1,229)=10.63, p=.001\right.$, partial $\left.\eta^{2}=.04\right)$, and participants in in the meta-dehumanization condition attributed more animalistic traits to Muslims $(M=$ $3.89, S D=1.34)$ than did those in the meta-humanization condition $(M=3.29, S D=$ $1.25 ; F(1,229)=12.52, p<.001$, partial $\left.\eta^{2}=.05\right) .{ }^{29}$

Finally, we examined whether the effects of experimental condition were mediated by identity threat and reciprocity. Theorizing suggests that identity threat and desires to reciprocate are intimately related (Branscombe et al., 1999a), supported by the high correlation we observed between these two constructs. Moreover, it follows from this theorizing that identity threat precedes desires to reciprocate a hostile perception. Thus, using the PROCESS Macro (Hayes, 2013; Model 6) we examined a serial mediation model, in which meta-dehumanization led to increased identity threat, leading to a desire to reciprocate, and thus, outgroup dehumanization. This analysis revealed a significant indirect effect, .19, 95\% CI $[.07, .35]$, suggesting the plausibility of this model. When these mediators were taken into account, the main effect of experimental condition on outgroup dehumanization was no longer significant, $b=.02, p=.90,95 \%$ CI: $-.24, .27 .^{30}$ Thus, individuals who received a meta-dehumanizing ( $v s$. metahumanizing) prime were significantly more likely to feel threatened and to feel a desire to reciprocate that hostile perception, together accounting for their tendency to dehumanize 
RUNNING HEAD: THEY SEE US AS LESS THAN HUMAN

the outgroup in kind.

In sum, the results of Study 7 provided empirical support for our theorizing about the reasons that meta-perceptions about the humanity attributed to the ingroup by an outgroup and individuals' own attributions of humanity to that group are linked. Specifically, our results suggested that when individuals learn that their group is dehumanized ( $v s$. humanized) by another group, they dehumanize that group in turn because they become more likely to feel that their social identity is threatened and thus show a greater desire to reciprocate that perception with hostility.

\section{General Discussion}

Ten studies document the importance of intergroup meta-dehumanization - that is, perceiving that one's group is dehumanized by another group. Whereas previous research has examined a range of negative meta-perceptions (e.g., Barlow, Sibley, \& Hornsey, 2012; Kamans et al., 2009; Owuamalam et al., 2013; Vorauer et al., 1998; Vorauer \& Kumhyr, 2001), no prior research has examined individuals' perception that their group is perceived by another group as less than fully human. Combining past research suggesting that individuals feel a threat to their social identity (and a desire to reciprocate) when their ingroup is derogated (e.g., Branscombe et al., 1999a; Doosje \& A. Haslam, 2005), with research documenting the unique role of dehumanization in shaping intergroup hostility (e.g., Andrighetto et al., 2014; Haslam, 2006; Kteily et al., 2015), we theorized that meta-dehumanization would uniquely predict aggressive outgroup attitudes and behavior via reciprocated outgroup dehumanization. Using large samples across a range of cultural contexts and significant real-world conflicts (i.e., the Israeli-Palestinian conflict, the Charlie Hebdo attacks, tensions between ethnic 
RUNNING HEAD: THEY SEE US AS LESS THAN HUMAN

Hungarians and the Roma population, and the U.S.-Iranian nuclear deal), we found consistent support for our predictions.

Examining the intergroup relationship between Americans and each of Arabs (Study 1a) and Muslims (Studies 1b and 1c), we began by providing evidence suggesting that meta-dehumanization causes outgroup dehumanization rather than the reverse. In a series of studies, we next documented the unique role of meta-dehumanization in predicting aggressive intergroup outcomes via its effects on outgroup dehumanization: among Americans who perceive they are dehumanized by Arabs (Study 2), ISIS (Study 5a), and Iranians (5b), among ethnic Hungarians who perceive they are dehumanized by the Roma (Study 3), and among Israelis who perceive they are dehumanized by Palestinians (Study 4). This relationship could not be accounted for by mere outgroup prejudice (Study 3) or meta-prejudice (Study 4). Indeed, by controlling for both these constructs in Studies 5a and 5b, we were able to document a novel dehumanizationspecific pathway from meta-perception to action (including aggressive intergroup attitudes and behavior). We further showed (Study 6) that meta-humanization can decrease outgroup dehumanization just as meta-dehumanization increases it, and provided evidence (Study 7) for the roles of identity threat and reciprocity desires in linking meta-perceptions about the humanity attributed to the ingroup by the outgroup on the one hand, and the humanity ratings ascribed to the outgroup on the other. Across studies, our effects could not be accounted for by political ideology (assessed via SDO, RWA and conservatism in Study 2, and conservatism in Studies 3, 5a, and 5b). ${ }^{31}$

In sum, we obtained strong evidence that meta-dehumanization is a unique metaperception heretofore unexamined, and one that likely contributes importantly to the 
RUNNING HEAD: THEY SEE US AS LESS THAN HUMAN

perpetuation of cycles of intergroup conflict and violence (Bar-Tal, 2000; Kelman, 1987).

Indeed, one troubling implication of the dehumanization-specific pathway from metaperception to action identified here is that aggressive responses on the part of group members who feel dehumanized by another group could subsequently increase metadehumanization perceptions on the other side, increasing the probability of escalating conflict. For example, Americans who think that Arabs dehumanize them are willing to behave more aggressively towards Arabs, which could in turn drive perceptions among Arabs that Americans view them as 'beasts', perpetuating a vicious cycle.

By examining dehumanization as a dynamic, interactive process involving both perceptions and meta-perceptions, our work importantly extends dehumanization research, which has typically examined outgroup perceptions in isolation (see Bastian \& Haslam, 2010, 2011 for exceptions in the interpersonal domain). By documenting a novel and consequential type of meta-perception, we also extend the scope of previous work on the harmful effects of negative meta-perceptions on intergroup interactions and encounters (e.g., Richeson \& Shelton, 2007; Vorauer et al., 1998) to the realm of dehumanization and aggressive intergroup relations. Just as recent research highlights the need to return to a consideration of blatant intergroup attitudes (Forscher, Cox, Graetz, \& Devine, 2015; Kteily et al., 2015), the present work suggests the importance of extending the examination of meta-perceptions from concerns about being disliked or subtly rejected in cross-group interactions, to a specific consideration of expectations about being openly dehumanized. Given, for example, the tenor of race relations in the U.S. today - exemplified by claims among members of both the African American and policing communities that the other side openly diminishes their humanity - the time is 
RUNNING HEAD: THEY SEE US AS LESS THAN HUMAN

ripe to give meta-dehumanization greater attention.

Our research also calls for greater efforts towards identifying interventions capable of attenuating the link between meta-dehumanization and outgroup dehumanization. One possibility is that asking individuals to engage in perspective-taking exercises (e.g., Hodson, Choma, \& Costello, 2009) could reduce the potency of metadehumanization. If individuals were tasked with putting themselves in the shoes of an outgroup individual who was on the receiving end of a hostile action previously committed by the ingroup (e.g., a drone strike that killed several of their family members), they might come to understand that even 'reasonable' people on the other side could, under certain circumstances, come to see one's group as savage. This understanding might help steer individuals who feel dehumanized by an outgroup away from reciprocal dehumanization and aggression, and towards more productive means of engaging with their counterpart.

Another potential approach could be to target identity threat. Study 7 suggested that people respond to meta-dehumanization with reciprocal outgroup dehumanization in part because meta-dehumanization causes them to feel that their ingroup identity is derogated. Given this, the use of group affirmation interventions may prove fruitful in reducing the link between identity threat and reciprocal dehumanization: If individuals faced with meta-dehumanization are able to affirm the ingroup's identity in other ways (for example, by focusing on its high standing among third party groups), they may be buffered from devaluation resulting from the outgroup's perceptions (see Bendersky, 2014, for a related approach).

Beyond influencing the way in which individuals respond to meta- 
RUNNING HEAD: THEY SEE US AS LESS THAN HUMAN

dehumanization, it would be interesting to examine the extent to which individuals' metadehumanization perceptions may be biased to begin with. Research suggests that individuals frequently overestimate the extent to which other groups' views differ from their own views (e.g., Keltner \& Robinson, 1997); therefore, individuals may perceive that they are more dehumanized by the outgroup than is objectively true. In Study 6, we observed that providing Americans with information that Muslims perceive Americans in highly humanized terms reduced Americans' dehumanization of Muslims.

Encouragingly, our intervention was based in part on actual perceptions that Muslims have of Americans (Esposito \& Mogahed, 2007). If individuals' baseline metadehumanization perceptions are more pessimistic than is warranted by reality, providing them with disconfirming humanizing information may be one effective route towards improving intergroup relations.

Despite the advances made by the current work, there are also a number of open theoretical questions that would benefit from further examination. For example, we considered here intergroup contexts relatively high in conflict, where we hypothesized that blatant meta-dehumanization would be particularly relevant and potent; the extent to which our findings would generalize to less hostile intergroup relations remains unknown. In more peaceful contexts, there may be a greater inclination among group members to acknowledge and repair dehumanization they perceive from respected outgroups. Moreover, there may be contexts in which meta-dehumanization is altogether less relevant than in those considered here. We think it less likely that metadehumanization of this nature would be as prevalent or relevant when considering, for example, U.S.-German relations, despite any tensions that may exist between them. In 
RUNNING HEAD: THEY SEE US AS LESS THAN HUMAN

such contexts, where tensions may exist in parallel with a mutual regard for the other side's humanity, we would expect meta-prejudice to play a more prominent role. In examining the relative roles of meta-dehumanization and meta-prejudice, future work could experimentally manipulate both constructs in one study. In Study 1a, we manipulated meta-dehumanization and held meta-prejudice constant. It would be interesting to examine how individuals respond to different combinations of learning that they are (or are not) dehumanized and disliked. In particular, it would be interesting to examine whether learning that one's ingroup is humanized improves intergroup relations beyond learning that one's ingroup is liked.

Another aspect of our work worth investigating further is the extent to which our findings extend to more subtle forms of meta-dehumanization. In this work we manipulated and assessed blatant forms of meta-dehumanization (and outgroup dehumanization $)^{32}$. These measures were particularly appropriate and relevant given the tenor of intergroup relations in the contexts we examined. Nevertheless, contemporary dehumanization research has also highlighted the importance of more subtle forms of dehumanization in 'everyday' contexts, such as denying outgroups complex secondary emotions, or traits central to human nature (e.g., Haslam, 2006, 2013; Leyens et al., 2000, 2007). If the outgroup does not explicitly perceive the ingroup as less evolved, but rather subtly conveys a sense that it is less relevant (e.g., Bastian \& Haslam, 2010) or that it has fewer complex emotions (Leyens et al., 2000), it is possible that individuals will respond primarily by feeling disheartened or saddened, rather than aggressive (see Bastian \& Haslam, 2010, 2011).

It will also be important for future work to consider how the effects of meta- 
RUNNING HEAD: THEY SEE US AS LESS THAN HUMAN

dehumanization might operate across the power spectrum. As with much research on intergroup meta-perceptions, we focused on relatively high power groups (i.e., Americans, Israelis, and ethnic Hungarians) and how they feel they are perceived by their lower-power/status counterparts. It remains to be seen how relatively low power groups (e.g., Arabs, Roma, African Americans) respond to the perception that they are seen as less than human by the high power outgroup. There are a number of reasons to suspect that the processes we identified might operate similarly — and perhaps even more powerfully — among low power groups. For one, as with high power groups, disadvantaged groups should experience derogation of the ingroup as aversive and seek to rectify it (Branscombe et al., 1999a), particularly with respect to meta-dehumanization, which has deep implications for the very worth of the group. Moreover, previous work among low power or disadvantaged groups has shown that they too can reciprocate negative meta-perceptions by expressing negativity towards, or endorsing collective action against, the outgroup (Branscombe et al., 1999b; Kamans et al., 2009;

Owuamalam et al., 2013). This is likely to be especially true in highly conflictual contexts, where low power group members (e.g., Palestinians) may be un-inclined to take on board the other side's (e.g., Israel) hostile perceptions of them. The idea that low power groups may be highly reactive to meta-dehumanization is also in line with research on divergent goals in inter-racial interactions. This research suggests that disadvantaged groups care more than advantaged groups about being respected and perceived as competent, whereas advantaged groups care more about being seen as moral (Bergsieker, Shelton, \& Richeson, 2010; see also Schnabel, Nadler, Ullrich, Dovidio, \& Carmi, 2009). It is highly plausible that meta-dehumanization maps particularly well on to the 
RUNNING HEAD: THEY SEE US AS LESS THAN HUMAN

perception that the ingroup is disrespected, which suggest that it may be especially impactful among low power groups.

On the other hand, there are also some reasons to predict that the link between meta-dehumanization and outgroup dehumanization might be attenuated among disadvantaged groups. For example, it is possible that those low power group members higher on the motivation to justify the system (Jost, Banaji, \& Nosek, 2004) may internalize even blatantly hostile perceptions that the outgroup holds of them. It is also possible that meta-dehumanization might come to be accepted by members of low power groups who lack collective efficacy (see Van Zomeren, Postmes \& Spears, 2008). The possibility that low power groups will be less likely than high power groups to respond to meta-dehumanization with outgroup dehumanization is bolstered by research showing that some disadvantaged groups (e.g., the Roma, or recent immigrants to Europe) do not (subtly) dehumanize the outgroup, despite clear evidence of their marginalization and maltreatment (Miranda, Gouveia-Pereira, \& Vaes, 2014; see also Capozza, Andrighetto, Di Bernardo, \& Falvo, 2012; Iatridis, 2013). Future work should examine both the link between meta-dehumanization and outgroup dehumanization as a function of group power, as well as likely moderators such as perceptions of system illegitimacy and group efficacy.

Future work would also benefit from further exploration of the nature of the causal relationship between meta-dehumanization and outgroup dehumanization. In the present work, we provided causal evidence that meta-dehumanization increases dehumanization (Studies 1a-1b; see also Studies 6-7), but did not find evidence for the reverse causal pathway (Study 1c). Nevertheless, despite the results we obtained in Study 
RUNNING HEAD: THEY SEE US AS LESS THAN HUMAN

1c, it would be premature to definitively rule out the possibility that outgroup dehumanization may also cause meta-dehumanization. For example, it is possible that individuals who dehumanize an outgroup may come to interpret that outgroup's actions in ways that confirm the idea that they dehumanize the ingroup, perhaps in order to legitimize pre-meditated aggression (see Castano \& Giner-Sorolla, 2006, for similar reasoning). Alternatively, individuals who dehumanize another group may simply infer that that group similarly dehumanizes their own through a perceived norm of reciprocal hostility (perhaps especially when two groups are already embroiled in violent conflict with one another). Longitudinal designs that examine the developmental course of metadehumanization and dehumanization — perhaps across an episode of intense intergroup conflict - would be well suited to continued examination of this question. ${ }^{33}$

Beyond further examining the causal relationship between meta-dehumanization and outgroup dehumanization, it will be useful for future research to consider the conditions under which meta-dehumanization versus outgroup dehumanization may play a relatively more important role in predicting intergroup aggression. For example, we observed that the correlation between dehumanization and intergroup attitudes tended to be somewhat stronger for ethnic Hungarians (with respect to Roma; Study 3) and Israelis (with respect to Palestinians; Study 4) than the correlations between metadehumanization and outcomes. In our American samples, on the other hand, these associations were generally closer in magnitude (with respect to Arabs and Iranians in particular; Studies 2 and $5 b)^{34}$. Although purely speculative, it is possible that this may have something to do with Americans' status as a global hegemon. Perhaps feeling dehumanized is particularly shocking to members of group possessing very high power, 
RUNNING HEAD: THEY SEE US AS LESS THAN HUMAN

directly provoking especially strong intergroup responses. Another difference between these samples that may account for this pattern is the fact that the Roma and Palestinians belong to the same social system as Hungarians and Israelis, respectively, whereas the group examined among Americans represent distant outgroups. Feeling dehumanized by a relatively unknown quantity may be particularly threatening, calling for especially aggressive responses.

Finally, it will be important for future work to consider the role that ingroup humanization may play in responses to meta-dehumanization. Vaes, Leyens, Paladino, and Miranda (2012) suggest that outgroup dehumanization and ingroup humanization may be independent (paralleling the distinction between ingroup love and outgroup hate; Brewer, 1999), and may arise for different reasons. For example, these authors argue that whereas ingroup humanization may be fairly common and is rooted in variables such as ingroup identification (see Demoulin et al., 2009), outgroup dehumanization may depend on contextual features such as the present of threat, and is more closely associated with variables such as ingroup glorification (see Leidner et al., 2010).

Given the conflictual contexts we examined, and because we were examining how "we see them" based on how "they see us", we focused here on outgroup dehumanization rather than ingroup humanization. Because ingroup and outgroup humanity attributions may be correlated, however, it is theoretically possible that our results might have been driven more by ingroup humanization in response to meta-dehumanization than by outgroup dehumanization per se. In supplemental analyses, we controlled for ingroup humanity attributions in order to test this possibility and obtained the same pattern of results throughout (see Supplementary Materials). This suggests that our observed 
RUNNING HEAD: THEY SEE US AS LESS THAN HUMAN

relationship between meta-dehumanization and reciprocal outgroup dehumanization is distinct from ingroup humanization.

On the other hand, when we examined the relationship between metadehumanization and ingroup humanity attributions controlling for outgroup ratings, we found inconsistent results: in most samples, meta-dehumanization was unassociated with ingroup humanization. In two cases (among Israelis and Hungarians), metadehumanization was surprisingly (but weakly) associated with lower ingroup humanity ratings, suggesting that participants' own perceptions may have been somewhat influenced by the outgroup's view (see also Bastian and Haslam, 2011). Consistent with this notion, in Studies 6 and 7, we observed that Americans who learned that they were humanized by Muslims were also more likely to humanize the ingroup (as well as humanizing the outgroup). Nevertheless, it is important to note that association between meta-dehumanization and dehumanization was consistent throughout when we assessed dehumanization in relative terms (i.e., as a difference score between ingroup and outgroup ratings). This suggests that even where meta-dehumanization might have been associated with less ingroup humanization, this was outweighed by its association with greater outgroup dehumanization. Future work should examine how individuals respond to meta-dehumanization in terms of their perception of the ingroup more directly. ${ }^{35}$

\section{Conclusion}

Our work provides clear evidence that meta-dehumanization is a novel and important meta-perception that can contribute to the perpetuation of highly consequential forms of intergroup conflict and hostility. Particularly given the recent spread of movements such as ISIS, the persistence of the Israeli/Palestinian conflict, and ongoing 


\section{RUNNING HEAD: THEY SEE US AS LESS THAN HUMAN}

racial and ethnic hostilities in societies around the world, determining how to blunt metadehumanization, or its effects on reciprocal dehumanization, may be critical to reducing vicious cycles of intergroup conflict.

\section{References}

Albarello, F., \& Rubini, M. (2012). Reducing dehumanisation outcomes towards Blacks: The role of multiple categorisation and of human identity. European Journal of Social Psychology, 42(7), 875-882. http://doi.org/10.1002/ejsp.1902

Altemeyer, B. (1988). Enemies of freedom: Understanding right-wing authoritarianism. San Francisco, CA, US: Jossey-Bass.

Andrighetto, L., Baldissarri, C., Lattanzio, S., Loughnan, S., \& Volpato, C. (2014). Humanitarian aid? Two forms of dehumanization and willingness to help after natural disasters. British Journal of Social Psychology, 53(3), 573-584. http://doi.org/10.1111/bjso.12066

Bain, P. G., Vaes, J., \& Leyens, J. P. (2014). Humanness and dehumanization. New York: Psychology Press.

Bandura, A., Barbaranelli, C., Caprara, G. V., \& Pastorelli, C. (1996). Mechanisms of moral disengagement in the exercise of moral agency. Journal of Personality and Social Psychology, 71(2), 364-374. http://doi.org/10.1037/0022-3514.71.2.364

Bandura, A., Underwood, B., \& Fromson, M. E. (1975). Disinhibition of aggression through diffusion of responsibility and dehumanization of victims. Journal of Research in Personality, 9(4), 253-269. http://doi.org/10.1016/0092-6566(75)90001-X

Barlow, F. K., Sibley, C. G., \& Hornsey, M. J. (2012). Rejection as a call to arms: Inter-racial hostility and support for political action as outcomes of race-based rejection in majority 
RUNNING HEAD: THEY SEE US AS LESS THAN HUMAN

and minority groups. British Journal of Social Psychology, 51(1), 167-177.

http://doi.org/10.1111/j.2044-8309.2011.02040.x

Bar-Tal, D. (2000). From Intractable Conflict Through Conflict Resolution To Reconciliation:

Psychological Analysis. Political Psychology, 21(2), 351-365.

http://doi.org/10.1111/0162-895X.00192

Bastian, B., Denson, T. F., \& Haslam, N. (2013). The Roles of Dehumanization and Moral Outrage in Retributive Justice. PLoS ONE, 8(4), e61842.

http://doi.org/10.1371/journal.pone.0061842

Bastian, B., \& Haslam, N. (2010). Excluded from humanity: The dehumanizing effects of social ostracism. Journal of Experimental Social Psychology, 46(1), 107-113.

http://doi.org/10.1016/j.jesp.2009.06.022

Bastian, B., \& Haslam, N. (2011). Experiencing Dehumanization: Cognitive and Emotional Effects of Everyday Dehumanization. Basic and Applied Social Psychology, 33(4), 295303. http://doi.org/10.1080/01973533.2011.614132

BBC News (2012, September 14). US missions braced for protests over anti-Islam film. $B B C$. Retrieved from http://www.bbc.com/news/world-middle-east-19596026.

Bendersky, C. (2014). Resolving ideological conflicts by affirming opponents' status: The Tea Party, Obamacare and the 2013 government shutdown. Journal of Experimental Social Psychology, 53, 163-168.

Bergsieker, H. B., Shelton, J.N., \& Richeson, J. A. (2010). To be liked versus respected:

Divergent goals in interracial interactions. Journal of Personality and Social Psychology, $99(2), 248-264$. 


\section{RUNNING HEAD: THEY SEE US AS LESS THAN HUMAN}

Bourhis, R. Y., Giles, H., Leyens, J. P., \& Tajfel, H. (1979). Psycholinguistic distinctiveness: Language divergence in Belgium. Language and social psychology, 158-185.

Branscombe, N. R., Ellemers, N., Spears, R., \& Doosje, B. (1999a). The context and content of social identity threat. In N. Ellemers, R. Spears, \& B. Doosje (Eds.), Social identity: Context, commitment, content (pp. 35-58). Oxford, England: Blackwell Science.

Branscombe, N. R., Schmitt, M. T., \& Harvey, R. D. (1999b). Perceiving pervasive discrimination among African Americans: Implications for group identification and wellbeing. Journal of Personality and Social Psychology, 77(1), 135-149.

http://doi.org/10.1037/0022-3514.77.1.135

Branscombe, N. R., \& Wann, D. L. (1994). Collective self-esteem consequences of outgroup derogation when a valued social identity is on trial. European Journal of Social Psychology, 24(6), 641-657. http://doi.org/10.1002/ejsp.2420240603

Brewer, M. B. (1999). The psychology of prejudice: Ingroup love or outgroup hate? Journal of Social Issues, 55, 429-444.

Bruneau, E., Jacoby, N., Kteily, N., Ligouri, L., \& Saxe, R. (under review). Denying humanity: Denying humanity: The distinct neural correlates of blatant dehumanization. Manuscript submitted for publication.

Buhrmester, M., Kwang, T., \& Gosling, S. D. (2011). A new source of inexpensive, yet highquality, data? Perspectives on Psychological Science, 6, 3-5. http://doi.org/10.1177/1745691610393980

Capozza, D., Andrighetto, L., Di Bernardo, G. A., \& Falvo, R. (2012). Does status affect intergroup perceptions of humanity? Group Processes and Intergroup Relations, 15 (3), 363-377. 


\section{RUNNING HEAD: THEY SEE US AS LESS THAN HUMAN}

Castano, E., \& Giner-Sorolla, R. (2006). Not quite human: Infrahumanization in response to collective responsibility for intergroup killing. Journal of Personality and Social Psychology, 90(5), 804-818. http://doi.org/10.1037/0022-3514.90.5.804

CBS News (2012, September 15). Widespread protests against U.S. over anti-Muslim film. CBS. Retrieved from http://www.cbsnews.com/news/widespread-protests-against-usover-anti-muslim-film/

Costello, K., \& Hodson, G. (2010). Exploring the roots of dehumanization: The role of animal-human similarity in promoting immigrant humanization. Group Processes \& Intergroup Relations, 13(1), 3-22. http://doi.org/10.1177/1368430209347725

Cuddy, A. J., Rock, M. S., \& Norton, M. I. (2007). Aid in the aftermath of Hurricane Katrina: Inferences of secondary emotions and intergroup helping. Group Processes \& Intergroup Relations, 10(1), 107-118. http://doi.org/10.1177/1368430207071344

Demoulin, S., Leyens, J.-P., Paladino, M.-P., Rodriguez- Torres, R., Rodriguez- Perez, A., \& Dovidio, J. (2004). Dimensions of "uniquely" and "non- uniquely" human emotions. Cognition and Emotion, 18(1), 71-96. http://doi.org/10.1080/02699930244000444

Demoulin, S., Cortes, B. P., Viki, T. G., Rodriguez-Perez, A., Rodriguez-Torres, R., Paladino, M. P., et al. (2009). The role of ingroup identification in infrahumanization. International Journal of Psychology, 44, 4-11. doi: 10.1080/00207590802057654

Devine, P. G., Evett, S. R., \& Vasquez-Suson, K. A. (1996). Exploring the interpersonal dynamics of intergroup contact. In R. M. Sorrentino \& E. T. Higgins (Eds.), Handbook of motivation and cognition, Vol. 3: The interpersonal context (pp. 423-464). New York, NY, US: Guilford Press. 


\section{RUNNING HEAD: THEY SEE US AS LESS THAN HUMAN}

Doosje, B., \& Haslam, S. A. (2005). What have they done for us lately? The dynamics of reciprocity in intergroup contexts. Journal of Applied Social Psychology, 35(3), 508-535. http://doi.org/10.1111/j.1559-1816.2005.tb02133.x

Ellemers, N., Wilke, H., \& Van Knippenberg, A. (1993). Effects of the legitimacy of low group or individual status on individual and collective status-enhancement strategies. Journal of Personality and Social Psychology, 64(5), 766-778. http://doi.org/10.1037/0022-3514.64.5.766

Enyedi Zs., Erős F. \& Fábián Z. (2001). Tekintélyelvűség és előítélet: Újabb magyarországi vizsgálatok. In Hunyadi Gy. \& Nguyen Luu Lan Anh (Eds.) Sztereotípia-kutatás. Hagyományok és irányok (391-402). Budapest: Eötvös Kiadó.

Esposito, J. L., \& Mogahed, D. (2007). Who speaks for Islam? What a billion Muslims really think. Gallup Press.

Forscher, P. S., Cox, W. T., Graetz, N., \& Devine, P. G. (2015). The motivation to express prejudice. Journal of Personality and Social Psychology, 109 (5), 791-812.

Frey, F. E., \& Tropp, L. R. (2006). Being Seen As Individuals Versus As Group Members: Extending Research on Metaperception to Intergroup Contexts. Personality and Social Psychology Review, 10(3), 265-280. http://doi.org/10.1207/s15327957pspr1003_5

Goff, P. A., Eberhardt, J.L., Williams, M.J., \& Jackson, M. C. (2008). Not yet human: implicit knowledge, historical dehumanization, and contemporary consequences. Journal of Personality and Social Psychology, 94(2), 292- 306.

Goff, P.A. Jackson, M. C., Di Leone, B.A. L., Culotta, C.M., \& DiTomasso, N. A. (2014). The essence of innocence: Consequences of dehumanizing Black children. Journal of Personality and Social Psychology, 106 (4), 526-545. 


\section{RUNNING HEAD: THEY SEE US AS LESS THAN HUMAN}

Haddock, G., Zanna, M. P., \& Esses, V. M. (1993). Assessing the structure of prejudicial attitudes: The case of attitudes toward homosexuals. Journal of Personality and Social Psychology, 65(6), 1105-1118. http://doi.org/10.1037/0022-3514.65.6.1105

Haslam, N. (2006). Dehumanization: An Integrative Review. Personality and Social Psychology Review, 10(3), 252-264. http://doi.org/10.1207/s15327957pspr1003_4

Haslam, N. (2014). What is dehumanization? In P. Bain, J. Vaes, \& J. P. Leyens (Eds.), Humanness and dehumanization (pp. 34-48). London, England: Psychology Press.

Haslam, N., Bain, P., Douge, L., Lee, M., \& Bastian, B. (2005). More human than you: Attributing humanness to self and others. Journal of Personality and Social Psychology, 89(6), 937-950. http://doi.org/10.1037/0022-3514.89.6.937

Haslam, N., \& Loughnan, S. (2014). Dehumanization and infrahumanization. Annual Review of Psychology, 65, 399-423.

Hayes, A. F. (2013). Introduction to Mediation, Moderation, and Conditional Process Analysis: A Regression-Based Approach. Guilford Press.

Hetherington, M., \& Suhay, E. (2011). Authoritarianism, Threat, and Americans' Support for the War on Terror. American Journal of Political Science, 55(3), 546-560. http://doi.org/10.1111/j.1540-5907.2011.00514.x

Ho, A. K., Sidanius, J., Pratto, F., Levin, S., Thomsen, L., Kteily, N., \& Sheehy-Skeffington, J. (2012). Social Dominance Orientation Revisiting the Structure and Function of a Variable Predicting Social and Political Attitudes. Personality and Social Psychology Bulletin, 38(5), 583-606. 


\section{RUNNING HEAD: THEY SEE US AS LESS THAN HUMAN}

Ho, A.K., Sidanius, J., Kteily, N., Sheehy-Skeffington, J., Pratto, F., Henkel, K., Foels, R., \& Stewart, A. (in press). The Nature of Social Dominance Orientation: Introducing the Social Dominance Orientation-7 Scale. Journal of Personality and Social Psychology.

Hodson, G., Choma, B.L., \& Costello, K (2009). Experiencing Alien-Nation: Effects of a simulation intervention on attitudes toward homosexuals. Journal of Experimental Social Psychology, 45, 974-978. http://doi.org/10.1016/j.jesp.2009.02.010

Hodson, G., \& Costello, K. (2007). Interpersonal disgust, ideological orientations, and dehumanization as predictors of intergroup attitudes. Psychological Science, 18(8), 691698. http://doi.org/10.1111/j.1467-9280.2007.01962.x

Hodson, G. \& MacInnis, C.C., \& Costello, K. (2014). (Over)Valuing "humanness" as an aggravator of intergroup prejudices and discrimination. In P.G. Bain, J. Vaes, \& J.-Ph. Leyens (Eds.), Humanness and dehumanization (pp. 86-110). London: Psychology Press.

Hornsey, M. J. (2008). Social Identity Theory and Self-categorization Theory: A historical review. Social and Personality Psychology Compass, 2(1), 204-222. http://doi.org/10.1111/j.1751-9004.2007.00066.x

Iatridis, T. (2013). Occupational status differences in attributions of uniquely human emotions. British Journal of Social Psychology, 52 (3), 431-449.

Jetten, J., Schmitt, M. T., \& Branscombe, N. R. (2013). Rebels without a cause: Discrimination appraised as legitimate harms group commitment. Group Processes and Intergroup Relations, 16(2), 159-172. http://doi.org/10.1177/1368430212445075

Jost, J. T., Banaji, M. R., \& Nosek, B. A. (2004). A Decade of System Justification Theory: Accumulated Evidence of Conscious and Unconscious Bolstering of the Status Quo. Political Psychology, 25(6), 881-919. 


\section{RUNNING HEAD: THEY SEE US AS LESS THAN HUMAN}

Kamans, E., Gordijn, E. H., Oldenhuis, H., \& Otten, S. (2009). What I think you see is what you get: Influence of prejudice on assimilation to negative meta-stereotypes among Dutch Moroccan teenagers. European Journal of Social Psychology, 39(5), 842-851. http://doi.org/10.1002/ejsp.593

Kelman, H. C. (1987). The Political Psychology of the Israeli-Palestinian Conflict: How Can We Overcome the Barriers to a Negotiated Solution? Political Psychology, 8(3), 347. http://doi.org/10.2307/3791039

Keltner, D., \& Robinson, R. J. (1997). Defending the status quo: Power and bias in social conflict. Personality and Social Psychology Bulletin, 23(10), 1066-1077.

Kteily, N., Ho, A. K., \& Sidanius, J. (2012). Hierarchy in the mind: The predictive power of social dominance orientation across social contexts and domains. Journal of Experimental Social Psychology, 48(2), 543-549.

http://doi.oorg/10.1016/j.jesp.2011.11.007

Kteily, N., Cotterill, S., Sidanius, J., Sheehy-Skeffington, J., \& Bergh, R. (2014). " Not One of Us": Predictors and Consequences of Denying Ingroup Characteristics to Ambiguous Targets. Personality and Social Psychology Bulletin, 40(10), 1231-1247. http://doi.org/10.1177/0146167214539708

Kteily, N., Bruneau, E., Waytz, A., \& Cotterill, S. (2015). 'The Ascent of Man': Theoretical and Empirical Evidence for Blatant Dehumanization. Journal of Personality and Social Psychology, 109 (5), 901-931. doi: 10.1037/pspp0000048

Leidner, B., Castano, E., Zaiser, E., \& Giner-Sorolla, R. (2010). Ingroup glorification, moral disengagement, and justice in the context of collective violence. Personality and Social Psychology Bulletin, 36(8), 1115-1129. http://doi.org/10.1177/0146167210376391 


\section{RUNNING HEAD: THEY SEE US AS LESS THAN HUMAN}

Leyens, J.-P., Demoulin, S., Vaes, J., Gaunt, R., \& Paladino, M. P. (2007). Infrahumanization: The Wall of Group Differences. Social Issues and Policy Review, 1(1), 139-172. http://doi.org/10.1111/j.1751-2409.2007.00006.x

Leyens, J.-P., Paladino, P. M., Rodriguez-Torres, R., Vaes, J., Demoulin, S., Rodriguez-Perez, A., \& Gaunt, R. (2000). The Emotional Side of Prejudice: The Attribution of Secondary Emotions to Ingroups and Outgroups. Personality and Social Psychology Review, 4(2), 186-197. http://doi.org/10.1207/S15327957PSPR0402_06

MacInnis, C. C., \& Hodson, G. (2012). Intergroup bias toward "Group X”: Evidence of prejudice, dehumanization, avoidance, and discrimination against asexuals. Group Processes \& Intergroup Relations, 15(6), 725-743. http://doi.org/10.1177/1368430212442419

Miranda, M., Gourveia-Pereira, M., \& Vaes, J. (2014). When in Rome...Identification and acculturation strategies among minority members moderate the dehumanization of the majority outgroup. European Journal of Social Psychology, 44 (4), 327-336.

Opotow, S. (1990). Moral Exclusion and Injustice: An Introduction. Journal of Social Issues, 46(1), 1-20. http://doi.org/10.1111/j.1540-4560.1990.tb00268.x

Owuamalam, C., Issmer, C., Zagefka, H., Klaßen, M., \& Wagner, U. (2014). Why Do Members of Disadvantaged Groups Strike Back at Perceived Negativity Towards the Ingroup? Journal of Community \& Applied Social Psychology, 24(3), 249-264. http://doi.org/10.1002/casp.2165

Owuamalam, C. K., Tarrant, M., Farrow, C. V., \& Zagefka, H. (2013). The effect of metastereotyping on judgements of higher-status outgroups when reciprocity and social image improvement motives collide. Canadian Journal of Behavioural Science/Revue 
RUNNING HEAD: THEY SEE US AS LESS THAN HUMAN

Canadienne Des Sciences Du Comportement, 45(1), 12-23.

http://doi.org/10.1037/a0030012

Paolini, S., Hewstone, M., Voci, A., Harwood, J., \& Cairns, E. (2006). Intergroup contact and the promotion of intergroup harmony: The influence of intergroup emotions. In R. Brown \& D. Capozza (Eds.), Social Identities: Motivational, Emotional and Cultural Influences (pp. 209-238). Hove, England: Psychology Press/Taylor \& Francis (UK).

Pratto, F., Sidanius, J., Stallworth, L. M., \& Malle, B. F. (1994). Social dominance orientation: A personality variable predicting social and political attitudes. Journal of Personality and Social Psychology, 67(4), 741.

Richeson, J. A., \& Shelton, J. N. (2007). Negotiating interracial interactions costs, consequences, and possibilities. Current Directions in Psychological Science, 16(6), 316320. http://doi.org/10.1111/j.1467-8721.2007.00528.x

Schnabel, N., Nadler, A., Ullrich, J., Dovidio, J. F., \& Carmi, D. (2009). Promoting reconciliation through the satisfaction of the emotional needs of victimized and perpetrating group members: The needs-based model of reconciliation. Personality and Social Psychology Bulletin, 35(8), 1021-1030.

Struch, N., \& Schwartz, S. H. (1989). Intergroup aggression: Its predictors and distinctness from in-group bias. Journal of Personality and Social Psychology, 56(3), 364-373. http://doi.org/10.1037/0022-3514.56.3.364

Tajfel, H., \& Turner, J. (2001). An integrative theory of intergroup conflict. In M. A. Hogg \& D. Abrams (Eds.), Intergroup relations: Essential readings (pp. 94-109). New York, NY, US: Psychology Press. 


\section{RUNNING HEAD: THEY SEE US AS LESS THAN HUMAN}

Tessler, M. (2003). Arab and Muslim Political Attitudes: Stereotypes and Evidence from Survey Research. International Studies Perspectives, 4(2), 175-181. http://doi.org/10.1111/1528-3577.402005

Waytz, A., Schroeder, J., \& Epley, N. (2014). The Lesser Minds Problem. In P. Bain, J. Vaes, \& J. P. Leyens (Eds.), Humanness and dehumanization (pp. 49-67). London, England: Psychology Press

Van Zomeren, M., Postmes, T., \& Spears, R. (2008). Toward an integrative social identity model of collective action: a quantitative research synthesis of three socio-psychological perspectives. Psychological Bulletin, 134 (4), 504-535.

Vaes, J., Leyens, J. P., Paladino, M. P., \& Miranda, P. (2012). We are human, they are not: Driving forces behind outgroup dehumanisation and the humanization of the ingroup. European Review of Social Psychology, 23 (1), 64-106.

Viki, G., Osgood, D., \& Phillips, S. (2013). Dehumanization and self-reported proclivity to torture prisoners of war. Journal of Experimental Social Psychology, 49, 325-328. http://dx.doi.org/10 .1016/j.jesp.2012.11.006

Vorauer, J. D., \& Kumhyr, S. M. (2001). Is this about you or me? Self-versus other-directed judgments and feelings in response to intergroup interaction. Personality and Social Psychology Bulletin, 27(6), 706-719. http://doi.10.1177/0146167201276006

Vorauer, J. D., Hunter, A. J., Main, K. J., \& Roy, S. A. (2000). Meta-stereotype activation: Evidence from indirect measures for specific evaluative concerns experienced by members of dominant groups in intergroup interaction. Journal of Personality and Social Psychology, 78(4), 690-707. http://doi.org/10.1037/0022-3514.78.4.690 


\section{RUNNING HEAD: THEY SEE US AS LESS THAN HUMAN}

Vorauer, J. D., Main, K. J., \& O’Connell, G. B. (1998). How do individuals expect to be viewed by members of lower status groups? Content and implications of metastereotypes. Journal of Personality and Social Psychology, 75(4), 917-937. http://doi.org/10.1037/0022-3514.75.4.917

Vorauer, J. D., \& Sakamoto, Y. (2008). Who cares what the outgroup thinks? Testing an information search model of the importance individuals accord to an outgroup member's view of them during intergroup interaction. Journal of Personality and Social Psychology, 95(6), 1467-1480. http://doi.org/10.1037/a0012631

Wildschut, T., Pinter, B., Vevea, J. L., Insko, C. A., \& Schopler, J. (2003). Beyond the group mind: a quantitative review of the interindividual-intergroup discontinuity effect. Psychological Bulletin, 129(5), 698-722.

Yzerbyt, V. Y., Judd, C. M., \& Muller, D. How do they see us? The Vicissitudes of Metaperception in Intergroup Relations. (2009). In Demoulin, S., Leyens, J. P., \& Dovidio, J. F. (Eds.), Intergroup misunderstandings: Impact of divergent social realities (pp. 63-100). Psychology Press.

\footnotetext{
${ }^{1}$ Including the participants who incorrectly answered the attention check questions resulted in the same significant pattern on our primary outcome measure (dehumanization), $F(1,208)=4.90, p=.03, \eta^{2}=.02$.

${ }^{2}$ We note that the experimental effect of the meta-dehumanization manipulation on Arab dehumanization was unaffected by including meta-prejudice ratings as a covariate (i.e., after its association with metadehumanization ratings was partialed out), $F\left(1,152=7.89, p=.006\right.$, partial $\eta^{2}=.05$.

3 We also examined difference scores (i.e., ratings of American vs. Arab humanity) rather than absolute dehumanization scores. We obtained similar results $\left(F=5.56, p=.02, \eta^{2}=.035\right)$. We focus here on absolute outgroup ratings rather than difference scores because the majority of our studies examine the
} 


\section{RUNNING HEAD: THEY SEE US AS LESS THAN HUMAN}

perception that the outgroup dehumanizes the ingroup in absolute (rather than relative) terms. Nevertheless, we obtain similar patterns across studies when a relative dehumanization score is used.

${ }^{4}$ One participant reported an age of 0 , which was recoded as a missing value.

${ }^{5}$ Results from a pre-test among a separate sample of non-Muslim native Americans on mTurk ( $n=209 ; M$ age $=36.73, S D=12.09 ; 51.2 \%$ female) indicated that this prime was successful in increasing metadehumanization (assessed on a 1-7 scale) relative to control (experimental condition: $M=4.95, S D=1.68$; control condition: $M=3.34, S D=1.58 ; F(1,133)=32.28, p<.001$, partial $\left.\eta^{2}=.20\right)$. This pretest included a third condition testing whether a meta-humanization prime (see Study 6) decreased meta-dehumanization relative to control.

6 As in the other studies with American participants, conservatism was assessed using 3 items, reflecting political party preference $(1=$ Strong Democrat; $7=$ Strong Republican $)$, and economic and social conservatism $(1=$ Very liberal; $7=$ Very conservative; $M=3.29, S D=1.56 ; \alpha=.91)$

${ }^{7}$ All analyses were significant when conservatism was not a covariate.

${ }^{8}$ Two of the animalistic traits were mentioned in the meta-dehumanization prime (i.e., 'savage' and 'selfcontrol'). Results were the same if these two items were removed from the animalistic scale and the blatant dehumanization composite.

${ }^{9}$ Results from a pretest using an independent sample of non-Muslim Americans on mTurk $(N=159 ; M$ age $=34.14, S D=11.50 ; 58.5 \%$ male) indicated that this prime was successful in increasing dehumanization of Muslims, assessed using the blatant dehumanization composite described in Study 1b. Control condition: $M$ $=-.24, S D=.79 ;$ Experimental condition: $M=.23, S D=.94 ; F(1,157)=11.56, p<.001$, partial $\eta^{2}=.07$ (effects were also significant using each of the Ascent scale and the animalistic trait ratings alone).

${ }^{10}$ Confidence intervals here and throughout the manuscript refer to the unstandardized coefficient.

11 The dataset included here uses the same dataset collected from this sample and reported in Kteily et al. (2015, Study 4). However, that paper examined the effects of blatant $v s$. subtle dehumanization of the Roma among Hungarians, and did not consider the role of meta-dehumanization, as it was beyond the scope of that research.

12 One participant entered a score of -100 on this item. This response was recoded as a missing value. 


\section{RUNNING HEAD: THEY SEE US AS LESS THAN HUMAN}

${ }^{13}$ We also included the Roma Attitudes Scale (Enyedi, Erös and Fábián, 2001). Because of its substantial overlap with the items about discriminatory policy, we did not include it as a separate outcome measure; we note that we observe the same results using this variable.

${ }^{14}$ Results were consistent when the entire sample was used.

${ }^{15}$ The experimental manipulation involved reading a text that either suggested that the U.S.' view of Israel was declining or continued to be positive. A MANOVA examining the effect of condition across the variables examined showed no significant effect of condition (Wilks' Lambda $=.96, F(21,1375.98)=$ $1.05, p=.40)$, though there was a small effect on support for aggressive policies, $F(3,485)=2.70, p=$ .045 , partial $\eta^{2}=.016$. To account for any effects of experimental condition, we residualized all variables on condition. We further note that the patterns of interest were similar across experimental condition.

$16 \mathrm{We}$ also assessed support for four other potential solutions. Although we focused on the most aggressive 'solution' (i.e., Expulsion of Palestinians), we note that we observed very similar results on other hostile solutions (e.g., "Absorbing the West Bank and Gaza into Israel without giving Palestinians a right to vote"). Meta-dehumanization also predicted decreased support for a two-state solution to the conflict.

17 Due to a programming error, the set of items including militaristic counter-terrorism and beyond were presented in the fixed order in which they appear in text.

1862 participants indicated that they were unfamiliar with the Charlie Hebdo incident. These participants did not receive the item asking about sending a message to families of the victims, nor the subsequent items assessing punitiveness towards the Hebdo attackers.

${ }^{19}$ For exploratory purposes, we also assessed four traits associated with mechanistic dehumanization (e.g., "mechanical and cold, like robots"). Since Ascent dehumanization is more closely related to animalistic (vs. mechanistic) dehumanization (Kteily et al., 2015, Study 5), we excluded these items from our blatant dehumanization composite. Nevertheless, we obtained comparable results when these items were included. ${ }^{20}$ Participants also rated the ingroup (i.e., Americans) on these same animalistic traits $(\alpha=.85 ; M=3.28$, $S D=.94)$.

21 We assessed two further items: "This nuclear deal is like giving your dog a treat after it pees on the rug", and "If you think you can tame a gorilla, it's only your fault if it returns to its true nature and bites". 


\section{RUNNING HEAD: THEY SEE US AS LESS THAN HUMAN}

Because of the conceptual overlap with animalistic dehumanization, we removed these items from our composite. Results are unaffected when these items are included.

22 Using TurkPrime's functionalities, we ensured that the samples in Studies 1b, 6, and 7 did not contain repeat participants.

${ }^{23}$ Results from the pre-test reported in Study $1 \mathrm{~b}$ indicated that this prime was successful in decreasing meta-dehumanization (assessed on a 1-7 scale) relative to control (experimental condition: $M=2.04, S D=$ 1.27; control condition: $M=3.34, S D=1.58 ; F(1,132)=28.08, p<.001$, partial $\left.\eta^{2}=.18\right)$.

${ }^{24}$ Participants in the control condition happened to be marginally higher in political conservatism, $F(1$, $209)=3.21, p=.08$ (assessed prior to our manipulation). Including conservatism as a covariate did not affect the significance of any of our analyses.

25 Two of the animalistic traits were mentioned in the meta-humanization prime (i.e., 'cultured and 'advanced'). Analyses excluding these two items from both the animalistic scale and the blatant dehumanization composite yielded equivalent results.

${ }^{26}$ Interestingly, we also observed that reading that Arabs perceived Americans as highly human increased Americans' ratings of their own humanity $(M=92.69, S D=11.72)$ on the Ascent scale relative to control $(M=88.81, S D=16.04), F(1,209)=4.23, p=.04$, partial $\eta^{2}=.02$, suggesting that participants' own ingroup perceptions were in line with the outgroup's view. We return to the topic of ingroup humanization in the general discussion.

27 Results were consistent when these participants were included in the analyses.

${ }^{28}$ In a pilot correlational study ( $n=178$; separate from Study 5 b) conducted prior to this experiment (focusing on meta-dehumanization with respect to Iran), we further examined the potential mediating role of perceiving a norm of conflict between the ingroup and outgroup (e.g., "It makes me think that hostility between us is just the norm"). We observed that whereas both identity threat and reciprocity significantly mediated the relationship between meta-dehumanization and dehumanization, perceived norm of conflict did not. Thus, we included only identity threat and reciprocity in this study.

${ }^{29}$ Analyses excluding traits mentioned in the primes yielded the same conclusions. 


\section{RUNNING HEAD: THEY SEE US AS LESS THAN HUMAN}

30 Because serial mediation models involve more assumptions, we also examined a simultaneous mediation model in which identity threat and desires for reciprocity were modeled in parallel. Examining these variables simultaneously (PROCESS Macro, Model 4), we observed that desires for reciprocity significantly mediated the effect of experimental condition on outgroup dehumanization (indirect effect: $.24,95 \% \mathrm{CI}: .08, .44)$, whereas identity threat was a marginally significant mediator (indirect effect: .18, 95\% CI: -.01, .40; i.e., just including 0).

31 We note that we obtained the same (or stronger) results throughout when these control variables were not included.

32 We note that our use of the term 'blatant' refers to the type (and not extent) of dehumanization perceptions (see also Kteily et al., 2015). Across our correlational samples, dehumanization levels on the (reverse-scored) Ascent scale ranged from a score of 18 (Study 2; Americans rating Arabs) to 50 (Study 3; Hungarians rating Roma). Although this certainly implies differences in the extent of outgroup dehumanization across these contexts, we consider both to reflect blatant dehumanization, because in each case participants consciously and explicitly lessen the full humanity of the outgroup on a metric that unambiguously captures animalistic associations. We note further that in all studies reported here, individuals rate the outgroup as significantly lower in humanity than the ingroup. For a broader theoretical and empirical discussion of the differences between blatant dehumanization and subtler, potentially unconscious, forms (such as the denial of secondary emotions), see Kteily et al., 2015.

33 We note that the cross-sectional models we examine in Studies 2-5b assume, in line with our experimental findings, that meta-dehumanization causes outgroup dehumanization. Although the causal model we propose is derived from our experimental findings and supported in our correlational data, this does not definitively rule out the plausibility of the reverse causal order (i.e., with dehumanization causing meta-dehumanization).

${ }^{34}$ We thank an anonymous reviewer for highlighting this pattern of results.

35 We note that the Ascent scale may not be ideal for assessing ingroup humanization, because a sizeable proportion of participants rate the ingroup at ceiling on the scale. Thus, an individual who feels dehumanized by the outgroup and who may otherwise have sought to humanize the group beyond the scale 
RUNNING HEAD: THEY SEE US AS LESS THAN HUMAN

maximum will not be able to register that response. In Study 5b, we examined animalistic trait attributions to the outgroup and ingroup in addition to the Ascent scale. For these traits, a smaller proportion of participants responded at floor when rating the ingroup, providing more 'room to move'. Thus, the use of these trait attributions may be more appropriate for those interested in directly examining ingroup humanization. Using these trait attributions in Study $5 \mathrm{~b}$, we found that meta-dehumanization was associated with outgroup dehumanization but not ingroup humanization. 
Table 1. Descriptive statistics and variable intercorrelations in Study 2.

\begin{tabular}{|c|c|c|c|c|c|c|c|c|c|c|c|}
\hline & 1 & 2 & 3 & 4 & 5 & 6 & 7 & 8 & 9 & 10 & 11 \\
\hline 1. Meta-Dehumanization & - & & & & & & & & & & \\
\hline 2. Dehumanization & $.38 * * *$ & - & & & & & & & & & \\
\hline 3. Surveillance of Arabs & $.43 * * *$ & $.42 * * *$ & - & & & & & & & & \\
\hline 4. Emotional Hostility & $.51 * * *$ & $.59 * * *$ & $.48 * * *$ & - & & & & & & & \\
\hline 5. Torture support & $.36^{* * *}$ & $.34 * * *$ & $.59 * * *$ & $.48^{* * *}$ & - & & & & & & \\
\hline 6. Drone support & $.37 * * *$ & $.30 * * *$ & $.64 * * *$ & $.47 * * *$ & $.59 * * *$ & - & & & & & \\
\hline 7. Arab distancing & $.32 * * *$ & $.27 * * *$ & $.36^{* * *}$ & $.52 * * *$ & $.28 * * *$ & $.44 * * *$ & - & & & & \\
\hline $\begin{array}{l}\text { 8. Opposition to Arab } \\
\text { immigration }\end{array}$ & $.29 * * *$ & $.43 * * *$ & $.45^{* * *}$ & $.47 * * *$ & $.31 * * *$ & $.39 * * *$ & $.44^{* * *}$ & - & & & \\
\hline 9. SDO & $.26^{* * *}$ & $.19^{* *}$ & $.32 * * *$ & $.35 * * *$ & $.44 * * *$ & $.42 * * *$ & $.44 * * *$ & $.18^{* *}$ & - & & \\
\hline 10. RWA & $.37 * * *$ & $.24 * * *$ & $.57 * * *$ & $.41 * * *$ & $.48^{* * *}$ & $.63^{* * *}$ & $.36^{* * *}$ & $.27 * * *$ & $.38 * * *$ & - & \\
\hline 11. Political Conservatism & $.26^{* * *}$ & .12 & $.40 * * *$ & $.29 * * *$ & $.34 * * *$ & $.42 * * *$ & $.39 * * *$ & $.22 * * *$ & $.50 * * *$ & $.57^{* * *}$ & - \\
\hline$M$ & 43.44 & 18.23 & 31.61 & 34.61 & 19.67 & 40.85 & 55.00 & 84.68 & 26.78 & 43.20 & 39.47 \\
\hline
\end{tabular}


Table 2. Unstandardized Indirect, Direct, and Total Effects of Meta-Dehumanization on Anti-Arab Attitudes and Policy Support via Dehumanization of Arabs in Study 2, Controlling for Political Ideology.

\begin{tabular}{lllllll}
\hline & Surveillance of Arabs & $\begin{array}{l}\text { Emotional } \\
\text { Hostility }\end{array}$ & $\begin{array}{l}\text { Torture } \\
\text { Support }\end{array}$ & $\begin{array}{l}\text { Drone } \\
\text { Support }\end{array}$ & $\begin{array}{l}\text { Arab } \\
\text { Distancing }\end{array}$ & $\begin{array}{l}\text { Opposition to Arab } \\
\text { Immigration }\end{array}$ \\
\hline Indirect Effect & $.07[.03, .13]$ & $.10[.06, .16]$ & $.04[.01, .09]$ & $.04[.01, .08]$ & $.04[.01, .09]$ & $.03[.01, .05]$ \\
Direct Effect & $.15[.06, .25]$ & $.18[.11, .25]$ & $.10[.01, .19]$ & $.09[.002, .18]$ & $.09[.001, .18]$ & $.02[-.01, .05]$ \\
Total Effect & $.23[.13, .33]$ & $.27[.20, .35]$ & $.14[.06, .23]$ & $.13[.05, .21]$ & $.13[.04, .21]$ & $.05[.02, .08]$ \\
\hline
\end{tabular}


Table 3. Descriptive statistics and variable intercorrelations in Study 3.

\begin{tabular}{|c|c|c|c|c|c|c|c|c|c|c|}
\hline & 1 & 2 & 3 & 4 & 5 & 6 & 7 & 8 & 9 & 10 \\
\hline 1. Meta-Dehumanization & - & & & & & & & & & \\
\hline 2. Dehumanization & $.35 * * *$ & - & & & & & & & & \\
\hline 3. Prejudice & $.35 * * *$ & $.57 * * *$ & - & & & & & & & \\
\hline $\begin{array}{l}\text { 4. Funding to Roma } \\
\text { Integration }\end{array}$ & $-.31 * * *$ & $-.48 * * *$ & $-.49 * * *$ & - & & & & & & \\
\hline 5. Support for discrimination & $.37 * * *$ & $.51 * * *$ & $.59 * * *$ & $-.63^{* * *}$ & - & & & & & \\
\hline $\begin{array}{l}\text { 6. Perceptions of Roma } \\
\text { homogeneity }\end{array}$ & $.22 * * *$ & $.23 * * *$ & $.18 * * *$ & $-.19 * * *$ & $.20 * * *$ & - & & & & \\
\hline 7. Responses to Injustice & $-.23 * * *$ & $-.32 * * *$ & $-.35 * * *$ & $.43 * * *$ & $-.56 * * *$ & $-.17 * * *$ & - & & & \\
\hline 8. Emotional Hostility & $.34 * * *$ & $.56 * * *$ & $.64 * * *$ & $-.54 * * *$ & $.65^{* * *}$ & $.25 * * *$ & $-.44 * * *$ & - & & \\
\hline 9. SDO & $.35 * * *$ & $.50 * * *$ & $.41 * * *$ & $-.37 * * *$ & $.48 * * *$ & $.19 * * *$ & $-.38 * * *$ & $.51 * * *$ & - & \\
\hline 10. Conservatism & $.17 * * *$ & $.23 * * *$ & $.27 * * *$ & $-.26^{* * *}$ & $.27 * * *$ & $.10^{* *}$ & $-.32 * * *$ & $.22 * * *$ & $.31 * * *$ & - \\
\hline$M$ & 32.41 & 50.44 & 72.49 & 29.06 & 41.51 & 39.56 & 63.86 & 45.77 & 23.55 & 50.00 \\
\hline$S D$ & 27.82 & 37.83 & 25.75 & 25.30 & 21.69 & 26.76 & 30.22 & 24.55 & 21.86 & 25.13 \\
\hline
\end{tabular}


Note. ${ }^{* * *} p<.001{ }^{* *} p<.01 * p<.05$ 
Table 4. Unstandardized Indirect, Direct, and Total Effects of Meta-Dehumanization on Anti-Roma Attitudes and Policy Support via (a) Dehumanization and (b) Prejudice towards Roma in Study 3, Controlling for Political Ideology.

\begin{tabular}{cccccc}
\hline & $\begin{array}{c}\text { Funding to Roma } \\
\text { Integration }\end{array}$ & $\begin{array}{c}\text { Support for } \\
\text { Discrimination }\end{array}$ & $\begin{array}{c}\text { Perceptions of } \\
\text { Roma } \\
\text { homogeneity }\end{array}$ & $\begin{array}{c}\text { Responses to } \\
\text { Injustice }\end{array}$ & $\begin{array}{c}\text { Emotional } \\
\text { Hostility }\end{array}$ \\
\hline $\begin{array}{c}\text { Indirect Effect } \\
\text { (Dehumanization) }\end{array}$ & $-.04[-.06,-.02]$ & $.02[.01, .04]$ & $.02[.01, .04]$ & $\begin{array}{c}-.01[-.03, \\
.00]\end{array}$ & $.03[.02, .05]$ \\
$\begin{array}{c}\text { Indirect Effect } \\
\text { (Prejudice) }\end{array}$ & $-.05[-.08,-.03]$ & $.06[.04, .09]$ & $.01[-.01, .03]$ & $\begin{array}{c}-.04[-.06,- \\
.02]\end{array}$ & $.08[.05, .11]$ \\
$\begin{array}{c}\text { Indirect Effect } \\
\text { (Total) }\end{array}$ & $-.10[-.13,-.07]$ & $.09[.06, .11]$ & $.03[.01, .05]$ & $\begin{array}{c}-.05[-.08,- \\
.03]\end{array}$ & $.11[.08, .15]$ \\
Direct Effect & $-.08[-.13,-.03]$ & $.09[.05, .13]$ & $.13[.06, .20]$ & $\begin{array}{c}-.05[-.12, \\
.02]\end{array}$ & $.04[-.00, .09]$ \\
& & & & $-.09[-.17,-$ & $.16[.11, .21]$ \\
Total Effect & $-.17[-.23,-.12]$ & $.17[.13, .22]$ & $.16[.09, .22]$ & $\begin{array}{c}.02] \\
.03]\end{array}$ \\
\hline
\end{tabular}


Table 5. Descriptive statistics and variable intercorrelations in Study 4.

\begin{tabular}{|c|c|c|c|c|c|c|c|}
\hline & 1 & 2 & 3 & 4 & 5 & 6 & 7 \\
\hline 1. Meta-Dehumanization & - & & & & & & \\
\hline 2. Meta-Prejudice & $.48 * * *$ & - & & & & & \\
\hline 3. Dehumanization & $.30 * * *$ & $.25 * * *$ & - & & & & \\
\hline 4. Support for Negotiations & $-.27 * * *$ & $-.19 * * *$ & $-.37 * * *$ & - & & & \\
\hline 5. Expulsion of Palestinians & $.25 * * *$ & $.19 * * *$ & $.27 * * *$ & $-.48 * * *$ & - & & \\
\hline 7. Emotional Hostility & $.27 * * *$ & $.36 * * *$ & $.40 * * *$ & $-.55 * * *$ & $.47 * * *$ & $.57 * * *$ & - \\
\hline$M$ & 41.34 & 72.32 & 55.31 & 58.91 & 36.46 & 41.09 & 65.71 \\
\hline$S D$ & 28.00 & 25.31 & 27.10 & 33.30 & 36.24 & 25.33 & 19.12 \\
\hline
\end{tabular}

Note. $* * * p<.001 * * p<.01 * p<.05$ 
Table 6. Unstandardized Indirect, Direct, and Total Effects of Meta-Dehumanization on Anti-Palestinian Attitudes and Policy Support via (a) Dehumanization in Study 4, Controlling for Meta-Prejudice.

\begin{tabular}{ccccc}
\hline & Support for Negotiations & $\begin{array}{c}\text { Expulsion of } \\
\text { Palestinians }\end{array}$ & $\begin{array}{c}\text { Support for } \\
\text { Aggressive } \\
\text { Policies }\end{array}$ & $\begin{array}{c}\text { Emotional } \\
\text { Hostility }\end{array}$ \\
\hline $\begin{array}{c}\text { Indirect Effect } \\
\text { (Dehumanization) }\end{array}$ & $-.08[-.13,-.05]$ & $.06[.03, .11]$ & $.09[.05, .13]$ & $.05[.03, .08]$ \\
Direct Effect & $-.19[-.30,-.07]$ & $.21[.08, .33]$ & $.14[.06, .22]$ & $.04[-.03, .10]$ \\
Total Effect & $-.27[-.39,-.15]$ & $.27[.14, .39]$ & $.22[.14, .31]$ & $.09[.02, .15]$ \\
\hline
\end{tabular}


Table 9. Descriptive statistics and variable intercorrelations in Study 5a.

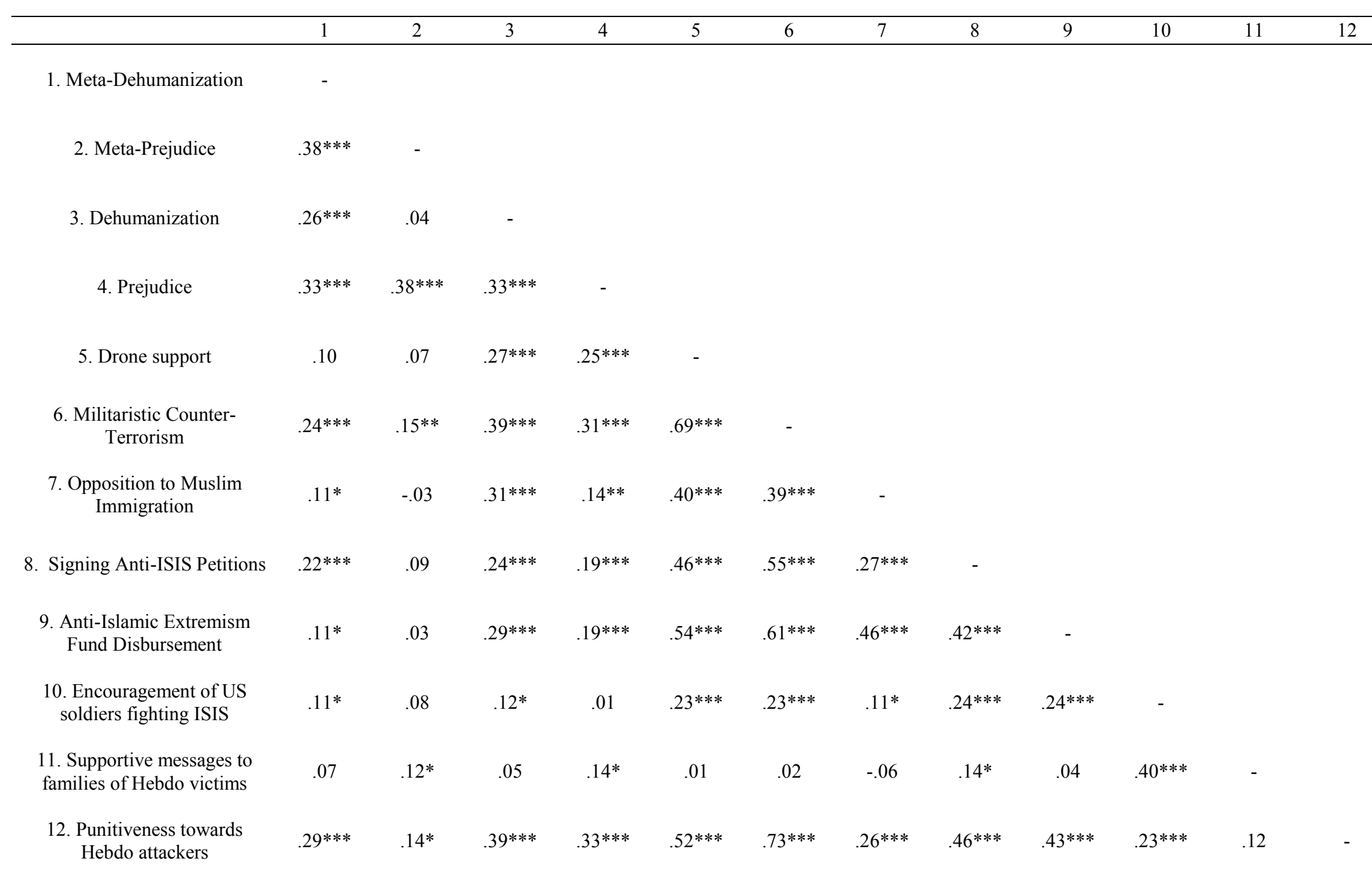


$.01 \quad .42 * * *$

$.48 * * *$

$.21 * * *$

$.40 * * *$

$.39 * * *$

$.16^{* *}$

$-.01 \quad .38^{* * *}$

M

70.52

90.53

38.17

85.87

45.75

49.98

85.05

5.92

32.95

19.73

25.33

61.90

43.45

$S D$

21.06

17.0

36.55

23.70

24.55

24.65

7.49

34.85

32.97

39.85

43.56

30.34

26.80

Note. ${ }^{* * *} p<.001^{* *} p<.01 * p<.05$ 


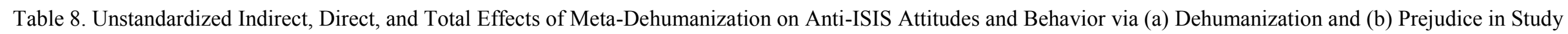
5a, Controlling for Meta-Prejudice and Political Ideology.

\begin{tabular}{|c|c|c|c|c|c|c|c|c|}
\hline & Drone Support & $\begin{array}{l}\text { Militaristic } \\
\text { Counter- } \\
\text { Terrorism }\end{array}$ & $\begin{array}{l}\text { Opposition to } \\
\text { Muslim } \\
\text { Immigration }\end{array}$ & $\begin{array}{l}\text { Signing } \\
\text { Anti-ISIS } \\
\text { Petitions }\end{array}$ & $\begin{array}{l}\text { Anti-Islamic } \\
\text { Extremism } \\
\text { Fund } \\
\text { Disbursement }\end{array}$ & $\begin{array}{c}\text { Encouragement } \\
\text { of US soldiers } \\
\text { fighting ISIS }\end{array}$ & $\begin{array}{l}\text { Supportive } \\
\text { Messages } \\
\text { to families } \\
\text { of Hebdo } \\
\text { victims } \\
\end{array}$ & $\begin{array}{c}\text { Punitiveness } \\
\text { towards } \\
\text { Hebdo } \\
\text { attackers }\end{array}$ \\
\hline $\begin{array}{l}\text { Indirect Effect } \\
\text { (Dehumanization) }\end{array}$ & $.04[.01, .09]$ & $.07[.04, .13]$ & $.02[.01, .04]$ & $\begin{array}{c}.05[.002 \\
.12]\end{array}$ & $.08[.03, .15]$ & $.003[.00, .01]$ & $\begin{array}{c}.001[- \\
.003, .004]\end{array}$ & $.10[.05, .17]$ \\
\hline $\begin{array}{l}\text { Indirect Effect } \\
\text { (Prejudice) }\end{array}$ & $.05[.02, .10]$ & $.05[.02, .09]$ & $\begin{array}{c}.01[-.002 \\
.04]\end{array}$ & $\begin{array}{c}.04[.01 \\
.09]\end{array}$ & $.05[.01, .09]$ & $\begin{array}{c}-.002[-.006 \\
.002]\end{array}$ & $\begin{array}{c}.004[.001 \\
.01]\end{array}$ & $.05[.05, .17]$ \\
\hline $\begin{array}{l}\text { Indirect Effect } \\
\quad(\text { Total })\end{array}$ & $.10[.04, .16]$ & $.12[.07, .18]$ & $.03[.02, .05]$ & $\begin{array}{c}.09[.04, \\
.17]\end{array}$ & $.12[.07, .21]$ & $\begin{array}{c}.002[-.003 \\
.007]\end{array}$ & $\begin{array}{c}.004[- \\
.001, .01]\end{array}$ & $.14[.08, .23]$ \\
\hline Direct Effect & $-.05[-.17, .08]$ & $.08[-.03, .19]$ & $.02[-.02, .06]$ & $\begin{array}{c}.21[.03, \\
.38]\end{array}$ & $.01[-.15, .18]$ & $\begin{array}{c}.009[-.006 \\
.02]\end{array}$ & $\begin{array}{l}-.001[-.01, \\
.01]\end{array}$ & $.20[.04, .37]$ \\
\hline Total Effect & $.05[-.07, .17]$ & $.20[.09, .32]$ & $\begin{array}{c}.05[.006 \\
.08]\end{array}$ & $\begin{array}{c}.29[.13, \\
.46]\end{array}$ & $.14[-.03, .30]$ & $.01[-.004, .03]$ & $\begin{array}{c}.002[-.01 \\
.02]\end{array}$ & $.35[.18, .51]$ \\
\hline
\end{tabular}


Table 9. Descriptive statistics and variable intercorrelations in Study 5b.

\begin{tabular}{|c|c|c|c|c|c|c|c|c|}
\hline & 1 & 2 & 3 & 4 & 5 & 6 & 7 & 8 \\
\hline 1. Meta-Dehumanization & - & & & & & & & \\
\hline 2. Meta-Prejudice & $.70^{* * *}$ & - & & & & & & \\
\hline $\begin{array}{l}\text { 3. Blatant Dehumanization } \\
\text { Composite }\end{array}$ & $.64 * * *$ & $.50 * * *$ & - & & & & & \\
\hline 4. Prejudice & $.48 * * *$ & $.46 * * *$ & $.67 * * *$ & - & & & & \\
\hline $\begin{array}{l}\text { 5. Opposition to the Iran } \\
\text { Nuclear Deal }\end{array}$ & $.60 * * *$ & $.50 * * *$ & $.62 * * *$ & $.46^{* * *}$ & - & & & \\
\hline $\begin{array}{l}\text { 6. Aggressive Actions towards } \\
\text { Iranians }\end{array}$ & $.60 * * *$ & $.49 * * *$ & $.63 * * *$ & $.54 * * *$ & $.73 * * *$ & - & & \\
\hline $\begin{array}{l}\text { 7. Signing Anti-Nuclear Deal } \\
\text { Petitions }\end{array}$ & $.35 * * *$ & $.25 * * *$ & $.36^{* * *}$ & $.26 * * *$ & $.57 * * *$ & $.43 * * *$ & - & \\
\hline 8. Conservatism & $.26 * * *$ & $.24 * * *$ & $.28 * * *$ & $.27 * * *$ & $.50 * * *$ & $.43 * * *$ & $.38 * * *$ & - \\
\hline$M$ & 44.10 & 66.49 & .00 & 47.12 & 45.19 & 29.46 & -7.10 & 39.73 \\
\hline$S D$ & 28.03 & 26.98 & .89 & 30.00 & 23.59 & 22.19 & 39.59 & 24.22 \\
\hline
\end{tabular}

Note. $* * * p<.001 * * p<.01 * p<.05$ 
Table 10. Unstandardized Indirect, Direct, and Total Effects of Meta-Dehumanization on Anti-Iranian Attitudes and Behavior via (a) Dehumanization and (b) Prejudice in Study 5b, Controlling for Meta-Prejudice and Political Ideology.

\begin{tabular}{cccc}
\hline & $\begin{array}{c}\text { Opposition to Iranian } \\
\text { Nuclear Deal }\end{array}$ & $\begin{array}{c}\text { Aggressive Actions } \\
\text { towards Iranians }\end{array}$ & $\begin{array}{c}\text { Signing anti-Nuclear } \\
\text { deal Petitions }\end{array}$ \\
\hline $\begin{array}{c}\text { Indirect Effect } \\
\text { (Dehumanization) }\end{array}$ & $.15[.09, .22]$ & $.13[.07, .21]$ & $.13[.01, .24]$ \\
Indirect Effect (Prejudice) & $.00[-.03, .03]$ & $.03[.002, .07]$ & $.00[-.05, .06]$ \\
$\begin{array}{c}\text { Indirect Effect } \\
(\text { Total) }\end{array}$ & $.15[.10, .21]$ & $.16[.10, .23]$ & $.13[.03, .22]$ \\
Direct Effect & $.23[.13, .33]$ & $.21[.11, .31]$ & $.29[.07, .51]$ \\
Total Effect & $.38[.28, .47]$ & $.37[.28, .46]$ & $.42[.22, .62]$ \\
\hline
\end{tabular}




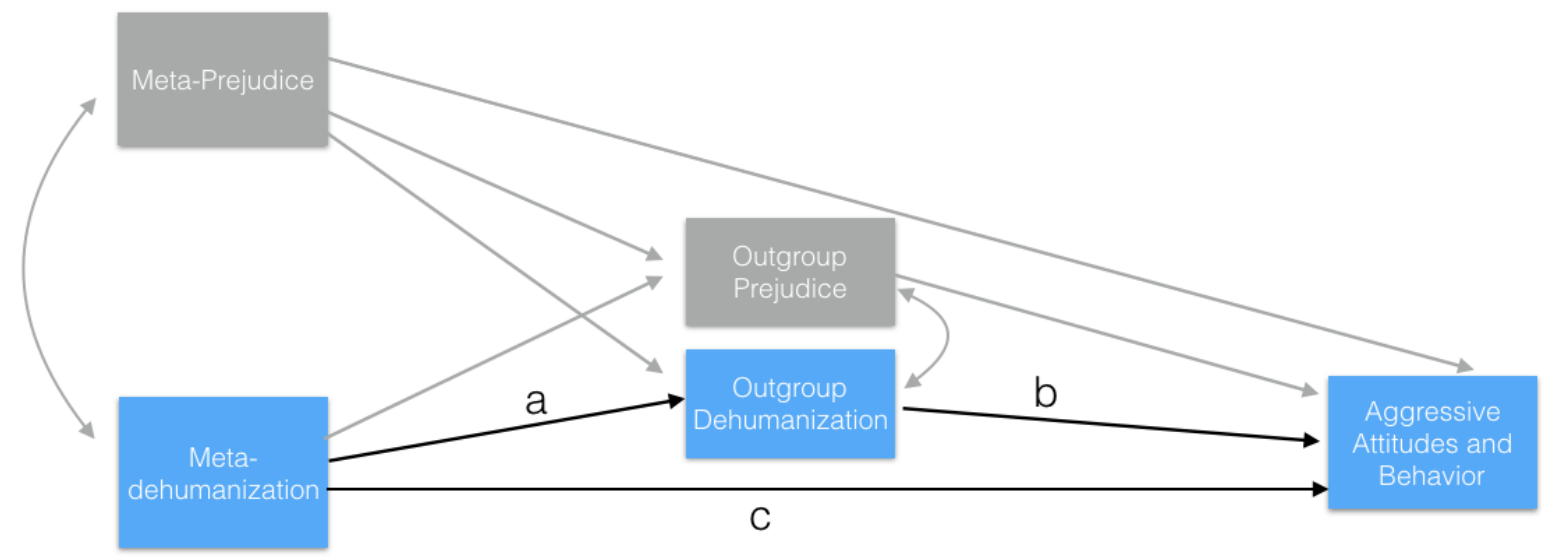

Figure 1. Conceptual diagram of the proposed theoretical model, in which Metadehumanization influences aggressive attitudes and behavior via outgroup dehumanization, controlling for Meta-Prejudice, outgroup prejudice, and political ideology (not shown). Primary variables (blue) and paths (black) of interest appear highlighted. 
"Using the image below, indicate using the sliders how evolved you consider the average members of each group to be:"

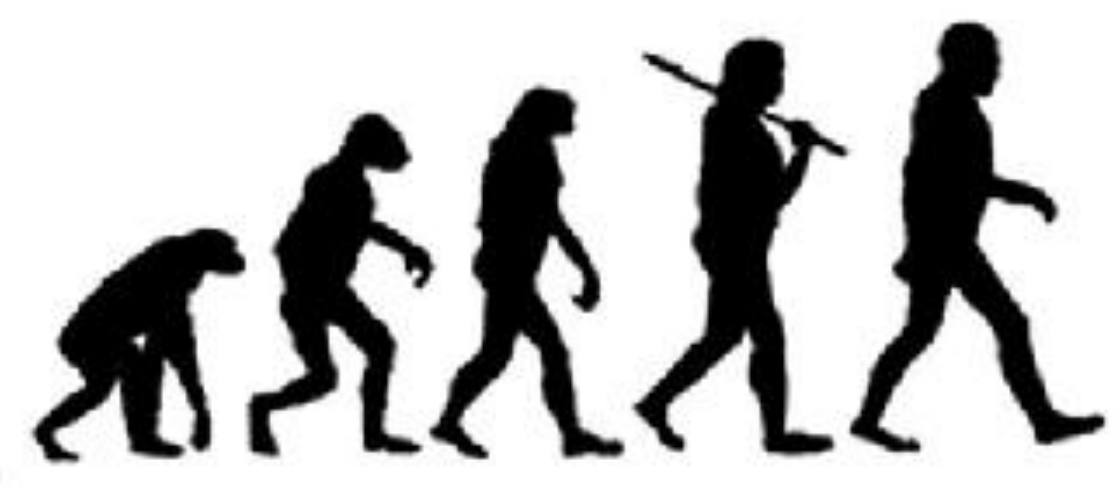

Figure 2. The 'Ascent of Man' measure of blatant dehumanization. This figure was originally published in Kteily, Bruneau, Waytz, \& Cotterill, 2015, JPSP, Figure 1. 


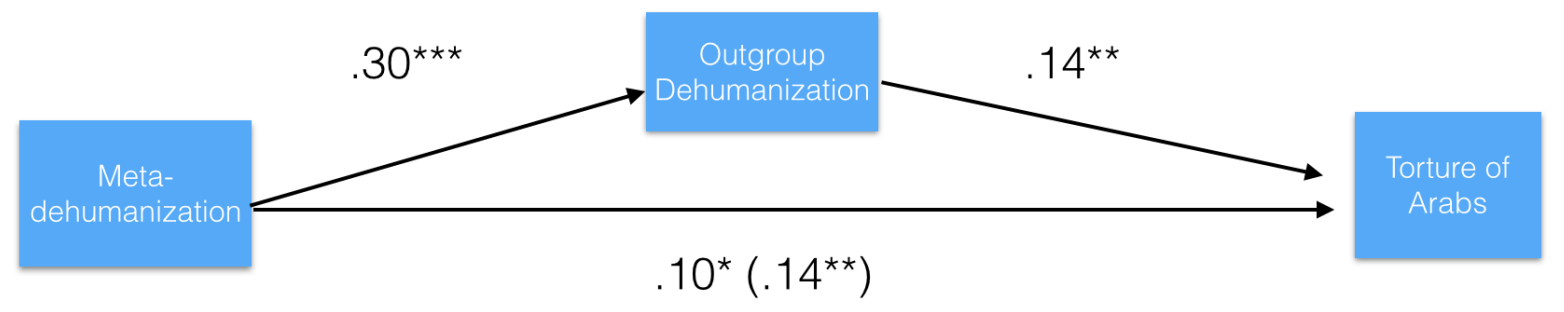

Figure 3. Path model showing effects of Americans' meta-dehumanization perceptions on support for torture of Arabs via outgroup dehumanization in Study 2 , controlling for political ideology (not shown). Numbers reflect unstandardized beta coefficients. ${ }^{* * *} p<.001 ;{ }^{* *} p<.01$ 


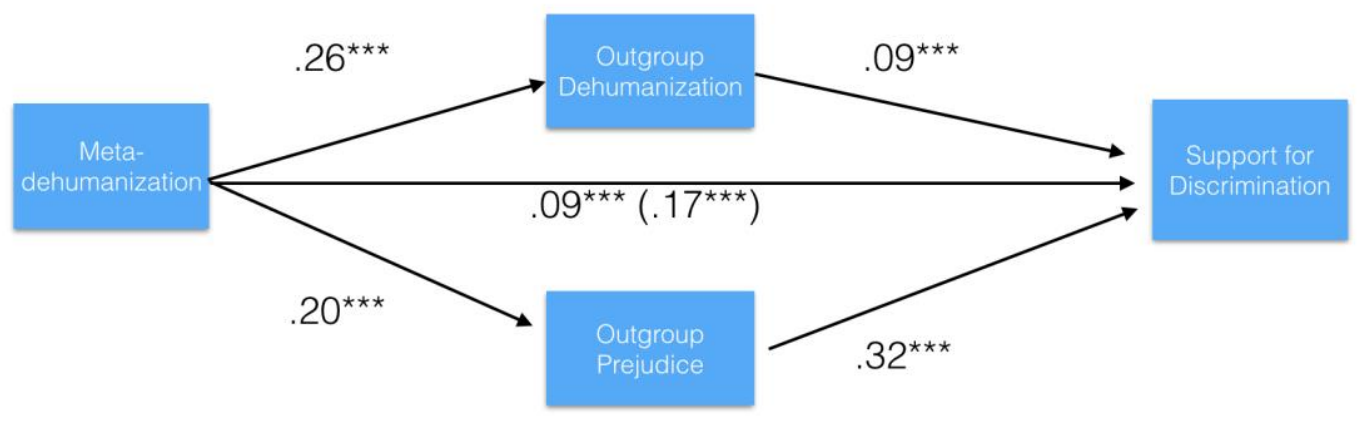

Figure 4. Path model showing effects of majority Hungarians' meta-dehumanization on support for aggressive policies towards the Roma in Study 3 via outgroup dehumanization and prejudice, controlling for political ideology (not shown). Numbers reflect unstandardized beta coefficients. ${ }^{* * *} p<.001$ 


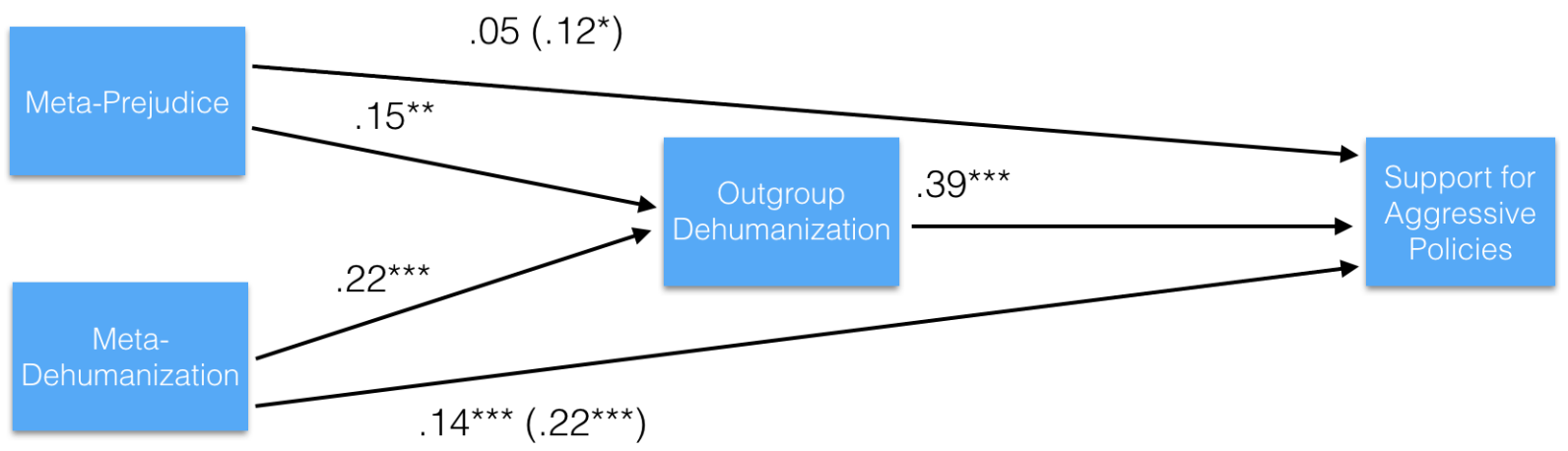

Figure 5. Path model showing effects of Israelis' meta-dehumanization on support for Aggressive policies towards Palestinians via dehumanization of Palestinians in Study 4 , controlling for meta-prejudice. Numbers reflect unstandardized beta coefficients. ${ }^{* * *} p<.001 ;{ }^{* *} p<.01 ;{ }^{*} p<.05$ 


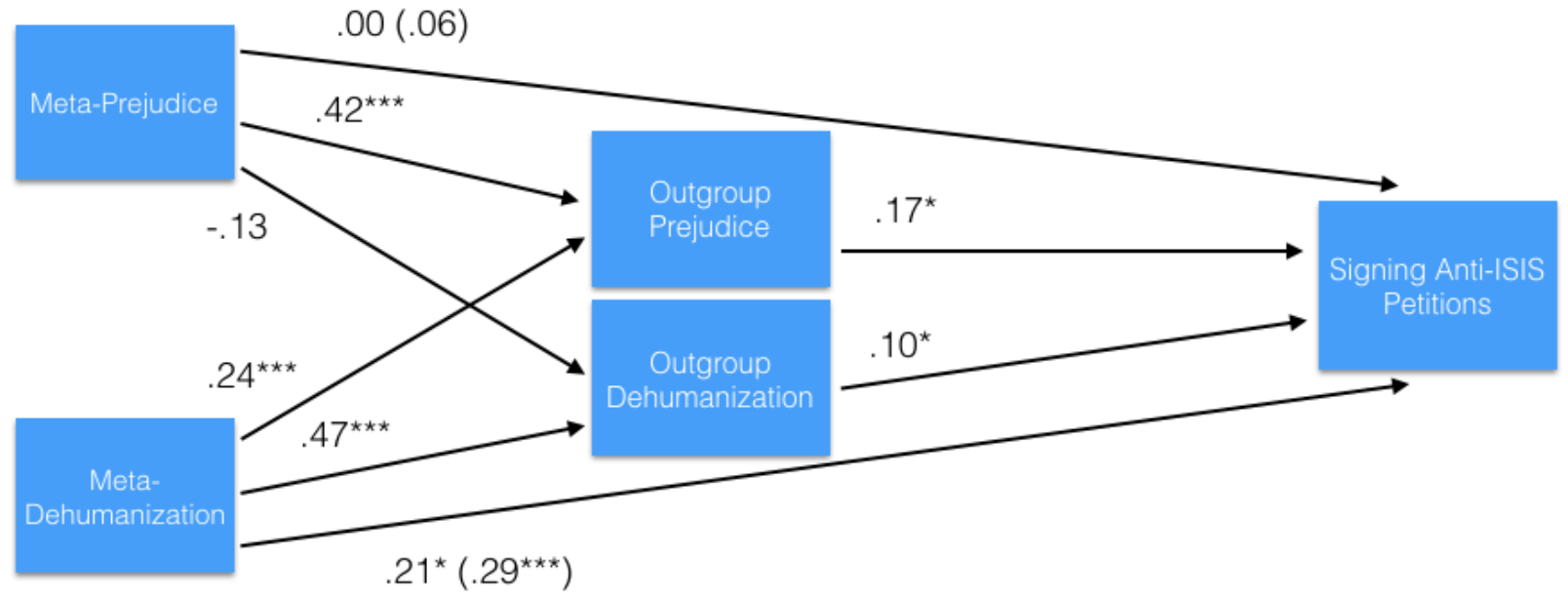

Figure 6. Path model showing effects of Americans' meta-dehumanization perceptions on signing anti-ISIS petitions via dehumanization of and prejudice towards ISIS in Study 5a, controlling for meta-prejudice and political ideology (not shown). Numbers reflect unstandardized beta coefficients. ${ }^{* * *} p<.001 ;{ }^{*} p<.05$ 